\begin{tabular}{|c|c|c|c|c|}
\hline \multirow{3}{*}{$\begin{array}{l}\text { 2. ECN Category } \\
\text { (mark one) } \\
\text { Supplemental } \\
\text { Direct Revision } \\
\text { Change ECN } \\
\text { Temporary } \\
\text { Standby } \\
\text { Supersedure } \\
\text { CancelNoid }\end{array}$} & \multirow{3}{*}{$\begin{array}{r}{[]} \\
{[\mathrm{X}]} \\
{[]} \\
{[]} \\
{[]} \\
{[]} \\
{[]}\end{array}$} & \multicolumn{2}{|c|}{$\begin{array}{l}\text { 3. Originator's Name, Organization, MSIN, } \\
\text { and Telephone No. } \\
\text { AJ Kostelnik, 08E00, S7-12, 3-0788 }\end{array}$} & $\begin{array}{l}\text { 4. USQ Re } \\
{[\mathrm{X}] \text { Yes [] }}\end{array}$ \\
\hline & & \multicolumn{2}{|c|}{$\begin{array}{l}\text { 6. Project Title/No. Work Order No. } \\
\text { Characterization Project }\end{array}$} & 7. Bldg./S \\
\hline & & \multicolumn{2}{|c|}{$\begin{array}{l}\text { 9. Document Numbers Changed by this. ECN } \\
\text { (includes sheet no. and rev.) } \\
\text { HNF-SD-WM-ETP-213 Rev. } 0\end{array}$} & 10. Relat \\
\hline $\begin{array}{l}\text { 12a. Modification Work } \\
\text { [] Yes (fill out Blk. 12b) } \\
{[\text { X] No (NA Blks. 12b, }} \\
12 \mathrm{c}, 12 \mathrm{~d} \text { ) }\end{array}$ & & $\begin{array}{l}\text { 12b. Work Package } \\
\text { No. } \\
\text { N/A }\end{array}$ & $\begin{array}{r}\text { Design Authori } \\
\text { Signatu }\end{array}$ & ineer \\
\hline
\end{tabular}

13a. Description of Change

13b. Design Baseline Document? [] Yes [X] No

This ECN releases the complete revision of HNF-SD-WM-ETP-213 Rev.0.

The revision of HNF-SD-WM-ETP-213 is changed from Rev:0 to Rev.1

The title is changed to:

"Engineering Task Plan for Upgrades to the Leveling Jacks on Core Sample Trucks \#3 and \#4"

14a. Justification (mark one)

Criteria Change $\quad[\mathrm{X}]$

As-Found

[1]

Design Improvement

[]

Environmental

$\mathrm{N} / \mathrm{A}$

5. Date

equired?

$10 / 7 / 98$ (Temp. or Standby ECN only)

N/A

Design Authority/Cog. Engineer Signature \& Date

14b. Justification Details

The ETP is revised to incorporate changes in scope.

USQ\#:Categorical Exclusion TF-96-0690 Rev.2

15. Distribution (include name, MSIN, and no. of copies)

RN Dale

ML Mcelroy

GP Janicek

RM Boger

JG Kristofski

HH Ziada
S7-12

S7-07

S7-12

S7-12

S7-01

R1-56
S7-12

S7-12

\$7-07

S7-12

\$7-03
EE Salinas

JA Ranschau

CE Hanson

$\mathrm{DH}$ Shuford
[1]

Facility Deactivation

Design Error/Omission
[] [] 


\section{ENGINEERING CHANGE NOTICE}

Page 2 of 2

1. ECN (use no. from pg. 1)

650919

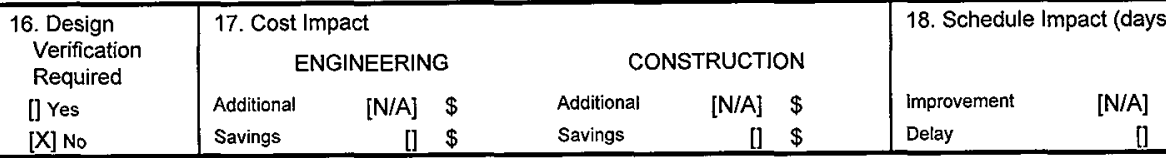

19. Change Impact Review: Indicate the related documents (other than the engineering documents identified on Side 1) that will be affected by the change described in Block 13. Enter the affected document number in Block 20.

$\begin{array}{ll}\text { SDDrDD } & {[]} \\ \text { Functional Design Criteria } & {[]} \\ \text { Operating Specification } & {[]} \\ \text { Criticality Specification } & {[]} \\ \text { Conceptual Design Report } & {[]} \\ \text { Equipment Spec. } & {[]} \\ \text { Const. Spec. } & {[]} \\ \text { Procurement Spec. } & {[]} \\ \text { Vendor Information } & {[]} \\ \text { OM Manual } & {[]} \\ \text { FSAR/SAR } & {[]} \\ \text { Safoty Equipment List } & {[]} \\ \text { Radiation Work Femit } & {[]} \\ \text { Environmental Impact Statement } & {[]} \\ \text { Environmental Report } & {[]} \\ \text { Environmental Permit } & {[]}\end{array}$

\begin{tabular}{|c|c|}
\hline [] & Seismis/Stress Analysis \\
\hline [1 & Stress/Design Report \\
\hline & Interface Control Drawing \\
\hline & Catibration Procedure \\
\hline & Installation Procedure \\
\hline & Maintenarco Procedure \\
\hline [1] & Engineering Procodure \\
\hline [1] & Operating Instruction \\
\hline 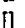 & Operating Procedufe \\
\hline DI & Operational Safety Requirement \\
\hline [1] & IEFD Drawing \\
\hline [] & Cell Arrangement Drawing \\
\hline [1] & Essential Material Specification \\
\hline [ & Fac. Proc. Samp. Schedule \\
\hline [] & Inspection Plan \\
\hline [1 & Inventory Adjusiment Request \\
\hline
\end{tabular}

\begin{tabular}{|c|}
\hline Tank Calibration Manual \\
\hline Health Physics Procedure \\
\hline Spares Multiple Unit Listing \\
\hline Test Procedures/Specification \\
\hline Component index \\
\hline ASME Coded Item \\
\hline Human Factor Consideration \\
\hline Computer Sofware \\
\hline Electric Ciroult Schedute \\
\hline ICRS Procedure \\
\hline Process Control ManuaVPlan \\
\hline Procoss Flow Chart \\
\hline Purchase Requisition \\
\hline Tickler File \\
\hline None \\
\hline
\end{tabular}

20. Other Affected Documents: (NOTE; Documents listed below will not be revised by this ECN.) Signatures below indicate that the signing organization has been notified of other affected documents listed below. Document Number/Revision

Document Number/Revision

Document Number Revision

\section{N/A}

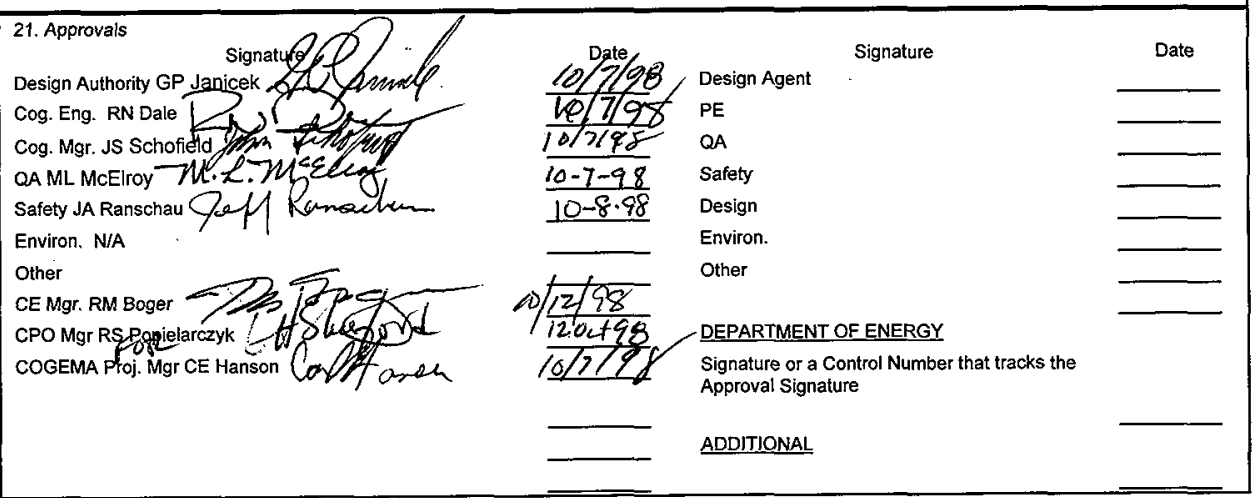




\title{
ENGINEERING TASK PLAN FOR UPGRADES TO THE LEVELING JACKS ON CORE SAMPLE TRUCKS \#3 AND \#4
}

\section{A.J. Kostelnik}

COGEMA Engineering Corporation, Richland, WA 99352

U.S. Department of Energy Contract DE-AC06-96RL13200

\author{
650919 \\ EDT/ECN: $648042^{2}$ 㮡rf.e $\quad$ UC: 2070 \\ Org Code: 08E00 \\ B\&R Code: EW3120074 \\ Charge Code: $\mathrm{N} 4 \mathrm{H} 3 \mathrm{C}$ \\ Total Pages: 4 (including this cover sheet)
}

Key Words: core sampling, RMCS, outrigger, jack,

\begin{abstract}
:
This Engineering Task Plan defines the requirements and deliverables of the activities associated with the upgrades of the leveling jacks and supporting structure on core sample trucks 3 and 4 .
\end{abstract}

TRADEMARK DISCLAIMER. Reference herein to any specific commercial product. process, or service by trade name, trademark. manufacturer, or otherwise. does not necessarily constitute or imply its endorsement, recomendation, or favoring by the United States Government or any agency thereof or its contractors or subcontractors.

Printed in the United States of America. To obtain copies of this document, contact: WHC/BCS Document Control Services. P.0. Box 1970. Mailstop H6-08, Richland WA 99352. Phone (509) 372-2420: Fax (509) 376-4989.

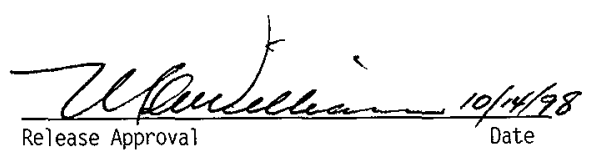

\section{Approved for Public Release}

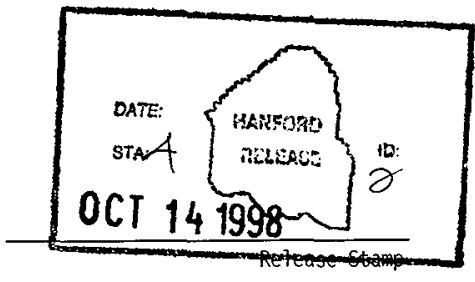


RECORD OF REVISION

(1) Document Number

HNF-SD-WM-ETP-213

Page 1

(2) Title

Engineering Task Plan for Upgrades to the Leveling Jacks on Core Sample Trucks \#3 and \#4

CHANGE CONTROL RECORD

\begin{tabular}{|c|c|c|c|}
\hline \multirow{2}{*}{ (3) Revision } & \multirow{2}{*}{ (4) Description of Change - Replace, Add, and Delete Pages } & \multicolumn{2}{|c|}{ Authorized for Release } \\
\hline & & (5) Cog. Engr. & (6) Cog. Mgr. \\
\hline 0 & (7) EDT 617997 & RN Dale & IS Schofield \\
\hline 1 RS & Complete revision (ECN 650919) & 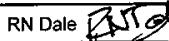 & 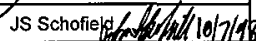 \\
\hline & & & \\
\hline & & & \\
\hline & & & \\
\hline & & & \\
\hline & & & \\
\hline & & & \\
\hline & & & \\
\hline & & & \\
\hline & & & \\
\hline & & & \\
\hline & & & \\
\hline & & & \\
\hline & & & \\
\hline & & & \\
\hline & & & \\
\hline & & & \\
\hline & & & \\
\hline & & & \\
\hline & & & \\
\hline & & & \\
\hline & & & \\
\hline & & & \\
\hline & & & \\
\hline & & & \\
\hline & & & \\
\hline & - & & \\
\hline & & & \\
\hline & & & \\
\hline & & & \\
\hline
\end{tabular}




\title{
ENGINEERING TASK PLAN FOR UPGRADES TO THE LEVELING JACKS ON CORE SAMPLE TRUCKS \#3 AND \#4.
}

\author{
A. J. Kostelnik \\ COGEMA Engineering Corporation
}

October 7, 1998 
TABLE OF CONTENTS

1 INTRODUCTION Page 1

2 SCOPE Page 1

3

DESCRIPTION Page 1

3.1 PHYSICAL DESCRIPTION Page 1

3.2 ENGINEERING TASKS Page 2

3.3 VERIFICATION Page 3

4 ORGANIZATION Page 3

5 COST and SCHEDULE

Page 4

5.1 ENGINEERING TASKS

Page 4

6 CONFIGURATION MANAGEMENT Page 5

7 QUALITY ASSURANCE Page 5

8 SAFETY Page 5

9 SYSTEM ENGINEERING Page 5 


\section{INTRODUCTION}

Characterizing the waste in underground storage tanks at the Hanford Site is accomplished by obtaining a representative core sample for analysis. Core sampling is one of the numerous techniques that have been developed for use given the environmental and field conditions at the Hanford Site. Core sampling is currently accomplished using either Push Mode Core Sample Truck \#1 or; Rotary Mode Core Sample Trucks \#2, 3 or 4.

Past analysis (WHC 1994) has indicated that the Core Sample Truck (CST) leveling jacks are structurally inadequate when lateral loads are applied. WHC 1994 identifies many areas where failure could occur. All these failures are based on exceeding the allowable stresses listed in the American Institute of Steel Construction (AISC) code. The mode of failure is for the outrigger attachments to the truck frame to fail resulting in dropping of the CST and possible overturning (Ref. Ziada and Hundal, 1996).

Out of level deployment of the truck can exceed the code allowable stresses in the structure. Calculations have been performed to establish limits for maintaining the truck level when lifting. The calculations and the associated limits are included in appendix A.

The need for future operations of the CSTs is limited. Sampling is expected to be complete in FY-2001. Since there is limited time at risk for continued use of the CSTs with the leveling controls without correcting the structural problems, there are several design changes that could give incremental improvements to the operational safety of the CSTs with limited impact on available operating time. The improvements focus on making the truck easier to control during lifting and leveling. Not all of the tasks identified in this ETP need to be performed. Each task alone can improve the safety.

This engineering task plan is the management plan document for implementing the necessary additional structural analysis. Any additional changes to meet requirements of standing orders shall require a Letter of Instruction from Numatec Hanford Company (NHC).

\section{SCOPE}

The scope of this Engineering Task Plan (ETP) is to provide the design for the installation of operator enhancements for the safe lifting and leveling of the core sample trucks.

\section{DESCRIPTION}

\subsection{PHYSICAL DESCRIPTION}

\subsubsection{Functional Design Criteria}

The requirements are included in the Design Compliance Matrix (LMHC 1998). 


\subsubsection{Structural Requirements}

The design of any modifications shall consider only the weight of the truck acting vertically in all possible positions. The factor of safety for the design shall be a minimum of 1.5 based upon the appropriate failure theory and tabulated AISC values.

Assumptions:

3.1.2. 1

Given that the leveling jacks have a safety class of GS there are

3.1.2.2 no procurement requirements such as material certifications etc.

3.1.2.3

3.1.2.4 The existing structural analysis produced for CST \#2 shall be considered to bound the design of CSTs \#3 and \#4.

The analysis shall consider the CST to be deployed in its worst possible out of level condition. (18 inch extension of 1 rear and the front jack).

Only the designs of CSTs \#3 and \#4 will be considered.

\subsection{ENGINEERING TASKS}

The deliverables will be in the form of released ECNs and USQ Screenings for the design changes. Required structural analysis for design modifications will be included as appendices to this ETP. The following tasks may be performed.

3.2.1 Perform analysis based upon actual possible deployment conditions of the existing design to determine actual capabilities and design structural modifications based upon results of the analysis. Existing analysis for lateral loads is based upon Truck \#2 design and does not include design changes made to increase the strength of the structure. Lateral loading analysis has not been performed for the Truck $3 \& 4$ design.

Recommended modifications could include adding gussets or stringers to strengthen the outrigger attachments to the truck frame and permanently limiting the deployment length of the bolsters. The benefit of performing this task is that the existing truck could prove to be adequate and no downtime is required for modifications.

3.2.2 Design and install electronic control system to lift and lower the truck within the limits specified. System may be commercially available. Would include installing larger diameter cylinders or higher pressure hydraulic supply for better lifting capability. Requires design and installation of hydraulic valves. The benefit of performing this task is that operator experience is no longer a factor for safe deployment. The current system used requires close attention by the operator to avoid exceeding the limits. The operator could be located a safe distance away from the truck when performing the lifting and levelling operation. 
3.2.3 Design and install a more user friendly control system for the operator to control the flow of the hydraulic fluid to the cylinders. (Replace the needle valves with sliding spool type valves. The benefit of performing this task is more rapid control of the hydraulic fluid to the cylinders allowing quick adjustments before the truck leans too far.

3.2.4 Install separate high pressure (2500 psi) hydraulic system for better control of the hydraulic jacks. Requires installation of PTO on truck transmission with hydraulic pump and reservoir. The current 1100 psi system on the drill rig provides barely adequate lifting capability. The benefit of performing this task is that the existing hydraulic jacks could be used to lift the truck with better control of the load.

3.2.5 Install larger hydraulic cylinders on the rear outriggers for better control of the load. Requires structural analysis. The benefit of performing this task is that the existing hydraulic system could be used to lift the truck with better control of the load.

3.2.6 Design and install a feedback system for the operator to monitor the level of the truck more easily. (Closed loop liquid level indicators.) The benefit of performing this task is that the operator would have immediate indication of the level of the truck without requiring communication with other operators.

3.2.7 Design and install devices to hold the truck axles close to the frame as if the load were on the wheels of the truck. The benefit of performing this task is that when the truck is required to be raised more than 18 inches it must be lifted in steps. During deployment the locks could be used to hold the wheels up, with about 14-15 inches of clearance below, for placing dunnage under the wheels and lifting the truck up higher in steps.

\subsection{VERIFICATION}

ECNs for the design changes shall receive an informal review per PHMC 1997b. Checking of the analysis will be completed per PHMC 1997b.

\section{ORGANIZATION}

Responsibilities are assigned to various organizations as identified below:

COGEMA Engineering Corporation will provide the engineering support as requested.
Responsible Manager:
C.E. Hanson
Responsible Engineer:
A.J. Kostelnik

Numatec Hanford Company (NHC) will provide funding and project management.

Responsible Manager: $\quad$ R.M. Boger 
Lockheed Martin Hanford Corporation (LMHC) will provide Cognizant Engineer support for review and USQ preparation.

Cognizant Manager: J.S. Schofield Cognizant Engineer: R.N. Dale

LMHC will also provide support for Design Authority, Quality Assurance and Safety.

Responsible Design Authority: $\quad$ G.P. Janicek

Responsible QA: M.L. McElroy

Responsible Safety: J.A. Ranschau

\section{COST and SCHEDULE}

Due to the fact that specific startup dates are unknown at this time, only estimates for duration of a given task are supplied.

\subsection{ENGINEERING TASKS}

\subsubsection{Perform analysis}

5.1.1.1 Estimated cost $=\$ 20 \mathrm{~K}+(\mathrm{ECNs}, \mathrm{USQ}$ and structural modifications as required by structural analysis.) ( 8 Weeks duration for analysis).

5.1.2 Design and install electronic control system to lift and lower the truck within the limits specified.
5.1.2.1
Estimated cost: Design $=400$ hours - ( 8 weeks duration), Hardware $=\$ 30 \mathrm{~K}$ (each truck)

5.1.3 Design and install a user friendly control system for the operator to control the flow of the hydraulic fluid to the cylinders.

5.1.3.1 Estimated cost: Design $=200$ hours $-(8$ weeks duration $)$ Hardware $=\$ 15 \mathrm{~K}$ (each truck)

5.1.4 Install separate high pressure (2500psi) hydraulic system for better control of the hydraulic jacks.

5.1.4.1 Estimated cost: Design $=120$ hours $-(6$ weeks duration $)$, Hardware $=\$ 5 \mathrm{~K}$ (each truck)

5.1.5 Install larger hydraulic cylinders on the rear outriggers for better control of the load.

5.1.5.1 Estimated cost: Design $=200$ hours $-(8$ weeks duration $)$, Hardware $=\$ 5 \mathrm{~K}$ (each truck) 
5.1.6 Design and install a feedback system for the operator to monitor the level of the truck more easily. (Closed loop liquid level indicators.)

5.1.6.1 Estimated cost: Design $=50$ hours $-(3$ weeks duration $)$, Hardware $=\$ 2 \mathrm{~K}$ (each truck)

5.1.7 Design and install devices to hold the truck axles close to the frame as if the load were on the wheels of the truck.

5.1.7.1 Estimated cost: Design $=100$ hours $-(3$ weeks duration $)$, Hardware $=\$ 5 \mathrm{~K}$ (each truck)

\section{CONFIGURATION MANAGEMENT}

All design changes shall be in the form of ECNs against the existing design configuration per procedure HNF-PRO-440 Engineering Document Change Control Requirements (PHMC 1997c).

\section{QUALITY ASSURANCE}

The Quality Assurance overview for the proposed activities shall be provided by LMHC. It is assumed that the budget for QA support is included in the general Characterization Project budget.

\section{SAFETY}

The Safety overview for the proposed activities shall be provided by LMHC. It is assumed that the budget for Safety support is included in the general Characterization Project budget.

\section{SYSTEM ENGINEERING}

This activity is necessary to support the characterization of the waste in the underground waste tanks on the Hanford site. This activity supports the Tank Farms task identified in the work breakdown structure (WBS) as task number 1.1.2.4.08.03 $\mathrm{NI}$, Core Sampling Systems (LMHC 1997). 
LMHC 1997 HNF-SP-1230 "Waste Characterization FY-98 Multi-Year Work Plan", September 26, 1997, Lockheed Martin Hanford Company, Richland, Washington

LMHC, 1998 "Baseline Design Compliance Matrix for the Rotary Mode Core Sampling System", HNF-SD-WM-CR-062, Rev.1, Lockheed Martin Hanford Corporation, Richland, Washington.

PHMC, 1997a, Engineering Design and Evaluation, HNF-PRO-97 Rev 0, Fluor Daniel Hanford Inc, Richland, Washington.

PHMC, 1997b, Design Verification Requirements, HNF-PRO-445 Rev 0, Fluor Daniel Hanford Inc, Richland, Washington.

PHMC, 1997c, Engineering Document Change Control Requirements, HNF-PRO-440 Rev 1; Fluor Daniel Hanford Inc, Richland, Washington.

WHC, 1994, Stress Analysis of Jacks, Frame and Bearing Connections, Drill Rod for Core Sampler Truck \#2, WHC-SD-WM-ER-392, Rev.0, Westinghouse Hanford Company, Richland, Washington.

Ziada and Hundal, 1996, Seismic Evaluation of Core Sampler Truck No. 2, Internal Memo, Westinghouse Hanford Company, Richland, Washington. 
HNF-SD-WM-ETP-213

Rev. 1

Appendix A 


\section{Administrative Controls for Core Sample Truck Outrigger Deployment}

\section{Discussion}

The load capability of the outriggers under loading conditions which are not vertical is limited. The attached calculations, for Trucks 3 and 4, identify limits for safe lifting and leveling operations.

When in the transport mode the jacks of the trucks are fully retracted to maximize ground clearance and the feet of the rear jacks are approximately 8 " above the ground and the front jack pad is approximately 15" above the ground. For the purpose of the controls in this letter, fully retracted is treated as 0 " extension. The heights referenced in this letter are all calculated from the $0^{\prime \prime}$ reference.

The purpose of the calculations was to give the largest safe operating envelope possible. Earlier analysis, WHC-SD-WM-ER-392 by Ziada, determined the Truck \#2 supporting structure has the capacity of 1400 pounds laterally when elevated $18^{\prime \prime}$ from 0 ". The $1400 \mathrm{lb}$ limit comes from $500 \mathrm{lbs}$ front to rear on each rear jack and $730 \mathrm{lbs}$ front to rear on the front jack along with $1250 \mathrm{lbs}$ side to side on each rear jack and $730 \mathrm{lbs}$ side to side on the front jack.

A separate analysis, WHC-SD-WM-ER-391 by Ziada, analyzed the Truck \#2 structure for rollover possibility. The analysis determined the truck, when deployed out of level by extending a single rear jack $18^{\prime \prime}$, would lean at an angle of $13^{\circ}$ but would not roll over.

The attached analysis looks at the loads that are applied to the structure of the truck to check on the structural capability of the outriggers and jacks. The analysis is based upon the lateral load limits in ER-392. The calculations apply the lateral load limits that were found for Truck \#2 and apply them to Trucks \#3 and \#4 because the designs are almost identical. Trucks \#3 and \#4 weigh $32000 \mathrm{lbs}, 2000 \mathrm{lbs}$ more than Truck \#2. The truck frame at the front of Trucks \#3 and \#4 is also approximately 20 inches higher off the ground than on Truck \#2: No checking was done on the limits in ER-392 to see if the added $2000 \mathrm{lbs}$ significantly affects the lateral load capability.

The conditions to be avoided are as follows:

1. Extending the jacks over 15" significantly reduces their capacity to the point where leaning beyond $3^{\circ}$ front to rear will overload the front jack and it could twist off shearing the mounting bolts on the jack attachment to the truck frame.

2. Extending the jacks over $5^{\prime \prime}$ significantly reduces their capacity to the point where leaning beyond $3^{\circ}$ from side to side will overload the front jack and could cause it to twist off, shearing the mounting bolts on the jack attachment to the truck frame.

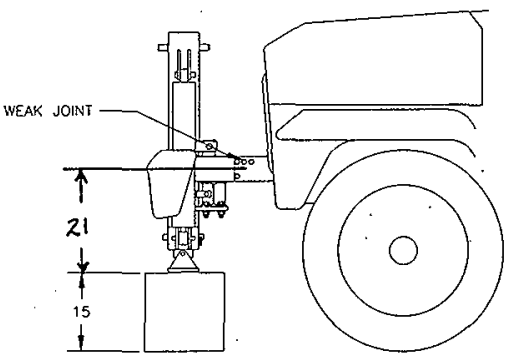

3. Extending the telescoping bolsters farther than would be necessary if deployed on level ground will significantly reduce the capability of the truck jacks to withstand lateral loads. (Over extension creates a longer moment arm for the lateral loads to act through.) 


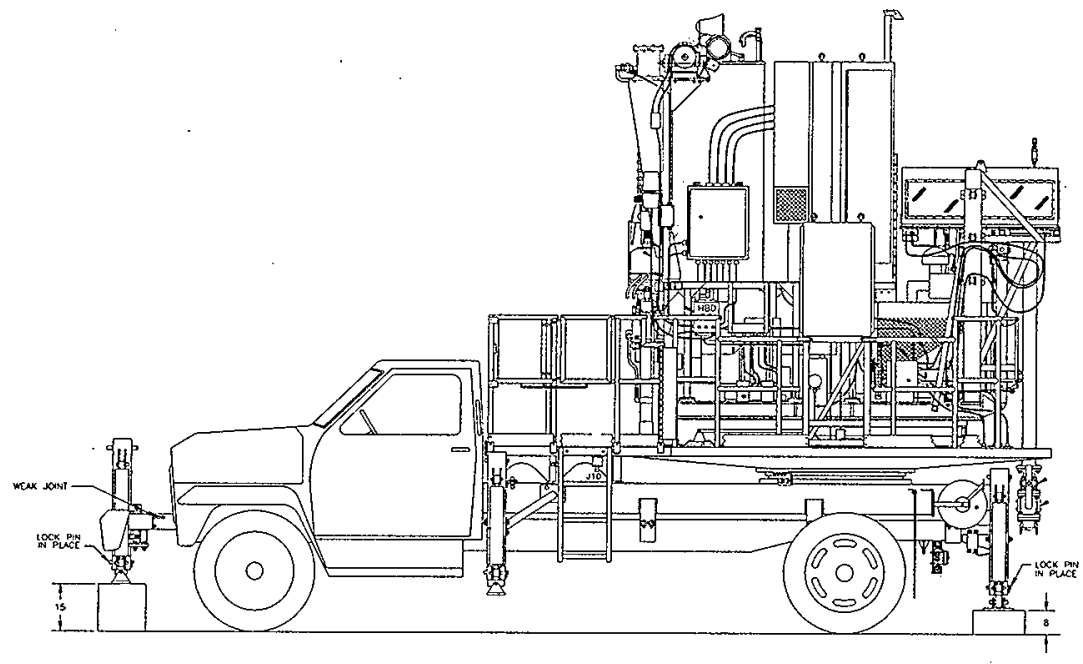

4. Truck out of level conditions also produce movement of the jack feet relative to each other. As the truck leans the distance between the jack feet changes. The change becomes significant when the truck is lifted higher. As the distance changes 1 of 3 things must happen. The jack feet must slide on the dunnage, the dunnage must lean, and/or the structure must bend.

\section{Controls}

The following "Controls" should be implemented to prevent operating under the conditions described above and exceeding the structural capabilities of the outrigger structures. The controls are prescribed to prevent the loading of the outriggers beyond the AISC code allowables. Because the failure mode of the weak connections is in shear, there is little plastic deformation that will occur before the material separates and the jacks fail. Failure could come rapidly without warning.

Control-1 The truck should be leveled within $5^{\circ}$ prior to deploying the truck jacks.

Basis: Leveling the truck prior to deploying the jacks will effectively shorten the bolster length and will prevent laterally loading the jacks with the lean of the truck. The truck could be leveled to within $5^{\circ}$ initially by driving on to dunnage. Then the truck should be levelled side to side using the rear jacks and front to rear leveling should be completed before proceding to lift the truck. 
Control-2 The bolsters should be limited to no more than an 18" extension. (Locking the collar, which is driven by the hydraulic cylinder, to the bolster will prevent telescoping the internal sections.) See sketch above.

Basis: The hydraulic cylinders have an $18^{\prime \prime}$ stroke. The $18^{\prime \prime}$ stroke is the basis for the analysis and the controls. Extension of the bolsters more than 18" reduces the lateral load bearing capability beyond the limits of these controls.

Control-3 The truck should be lifted level within $3^{\circ}$ (The angle of $3^{\circ}$ is approximately $4^{\prime \prime}$ difference in stroke length of the hydraulic cylinders from side to side and $15^{\prime \prime}$ difference front to rear). If $3^{\circ}$ is exceeded the ascent of the truck should be halted and the high side of the truck lowered back to level prior to continuing to raise.

Basis: The point in which the RMCS is laterally loaded beyond the AISC Code allowables is $3^{\circ}$ when Control-2 is satisfied.

\section{Precautions}

The following "Precautions" are to limit the damage that would be incurred if the truck failed structurally. Operating within the administrative controls above will not stress the truck beyond the allowable stresses and should prevent it from failing.

Precaution-1 The locking collars on the bolsters should be continuously adjusted up the bolster at every opportunity to prevent the free descent of the truck should a hydraulic cylinder fail or become overloaded.

Basis: Failure of a hydraulic ram would cause the truck to free fall to the locking collar. The collar would prevent the truck from building enough momentum as it fell to do more significant damage. An unrestrained fall could produce enough momentum to slide the truck off of the dunnage or cause the outrigger structure to fail. Overloading caused by out of level condition beyond $6^{\circ}$ can cause the truck to begin descending on the overloaded ram and rapidly increase the lateral load.

Precaution-2 Dunnage should be stacked under the wheels or frame in 4 " increments as the truck is raised.

Basis: This control will help to catch the truck should the bolsters fail due to lateral loads. This control provides additional protection from overloading or free descent of a jack that causes an outrigger failure.

Precaution-3 Inadvertent contact between the outriggers and the ground during transport should be prevented (such as dragging the jack pads when crossing ditches). If the outriggers contact the ground during transport they should be inspected for cracked welds, bent components, and joint misalignment prior to deployment. All components from the outrigger foot to the joint with the truck frame should be checked.

Basis: Prevents deployment with damaged structural members. 
Precaution-4 The dunnage should have a large enough surface (at least 2 times the jack foot dimensions) and the jack foot centered on the dunnage to prevent the truck from sliding off the dunnage.

Basis: Lifting the truck out of level or rocking it as it goes up can cause the jack feet to "walk" on the dunnage. This could significantly shift the weight distribution on the dunnage causing it to tip or worst case the foot could fall off the side.

\section{Truck \#2}

Truck \#2 was also analyzed for limits related to the lateral loading conditions. It weighs approximately 2000 pounds less than Trucks 3 and 4 and the front jack is mounted lower. The two features combined make the Truck \#2 structure relatively stronger than Trucks 3 and 4. The controls applied to Trucks 3 and 4 are more restrictive (ie. the controls of Trucks 3 and 4 envelope the controls of Truck 2) than would be applied to Truck 2. Two sets of controls are not given because it would increase the likelihood that the wrong controls would be applied in the field. 


\section{Prepared by: AJ Kostelnik Prepared by: HH Zlada}

Date: 911198

\section{Front to Rear Loading with the Front Higher than the Rear}

Calculations to show how the rear jack loads increase when the front of the truck is raised higher than the rear and shifts the center of gravity backwards. Assume Trucks 3 \& 4 weigh 32000 pounds. Reference diagram titled "FRONT HIGHER THAN REAR" (Page 14).

$\Delta L:=0 . .18 \quad$ Difference in jack length.

$\phi_{\Delta L}:=\operatorname{atan}\left(\frac{\Delta L}{282}\right) \quad$ Angle produced by front higher than the rear: Angle from level.

Weight on front jack (Derived from moments about rear jack pad)

Weight on rear jacks.

$F F J_{\Delta L} ;=W F_{\Delta L} \cdot \cos \left(\phi_{\Delta L}\right)$

$$
W_{\Delta L}:=32000 \cdot 1 \mathrm{bf} \cdot \frac{110 \cdot \cos \left(\phi_{\Delta L}\right)-(46.5) \cdot \sin \left(\phi_{\Delta L}\right)}{282 \cdot \cos \left(\phi_{\Delta L}\right)+\Delta L \cdot \sin \left(\phi_{\Delta L}\right)}
$$

$W R_{\Delta L}:=32000 \cdot 1 \mathrm{bf}-W_{\Delta L}$ FRJ $:=\frac{W \mathrm{LL}}{2} \cdot \cos \left(\phi_{\Delta L}\right) \quad$ Axial force acting on the front and each rear jack cylinder.

Force component acting perpendicular to the bolsters. (The force component actually produces a bending moment in the bolster. For comparison it is projected to act at the jack pad. The "force" is produced by the weight of the truck on the leaning bolsters.)

FFJH ${ }_{\Delta L}:=W F_{\Delta L} \cdot \sin \left(\phi_{\Delta L}\right)$

\begin{tabular}{|c|c|c|}
\hline$\Delta L$ & $\phi_{\Delta L} \cdot \frac{180}{\pi}$ & $\frac{W F_{\Delta L}}{16 f}$ \\
\hline 0 & 0 & $\longdiv { 1 2 4 8 2 }$ \\
\hline 7 & 0.2 & 12463 \\
\hline 2 & 0.4 & 12444 \\
\hline 3 & 0.6 & 12425 \\
\hline 4 & 0.8 & 12405 \\
\hline 5 & 7 & 12385 \\
\hline 6 & 1.2 & 12364 \\
\hline 7 & 0.4 & 72344 \\
\hline 8 & 1.6 & 12323 \\
\hline 9 & 1.8 & 72307 \\
\hline 10 & 2 & 72280 \\
\hline रा & 2.2 & 12258 \\
\hline 12 & 2.4 & 12236 \\
\hline 73 & 2.6 & 12213 \\
\hline 14 & 2.8 & 12190 \\
\hline 15 & 3 & 12167 \\
\hline 16 & 3.2 & 12144 \\
\hline 17 & 3.4 & 12120 \\
\hline 18 & 3.7 & 12096 \\
\hline
\end{tabular}

$\mathrm{FRJH}_{\Delta L}:=\frac{W R}{2} \cdot \sin (\phi L L)$

\begin{tabular}{|c|c|c|c|}
\hline$\frac{{ }^{F F J}{ }_{\Delta L}}{\text { tbf }}$ & $\frac{\mathrm{FRJ}_{\Delta \mathrm{L}}}{\mathrm{ISF}}$ & ${ }_{\mathrm{Ibf}}^{\mathrm{FFJH}_{\Delta \mathrm{L}}}$ & $\frac{\text { FRJH }}{767}$ \\
\hline 12482 & 9759 & 0 & 0 \\
\hline 12463 & 9768 & 44 & 35 \\
\hline 12444 & 9778 & 88 & 69 \\
\hline 12424 & 9787 & 132 & 704 \\
\hline 12404 & 9797 & 776 & 139 \\
\hline 12383 & 9806 & 220 & 174 \\
\hline 12362 & 9816 & 263 & 209 \\
\hline 12340 & 9825 & 306 & 244 \\
\hline 12318 & 9835 & 349 & 279 \\
\hline 12295 & 9844 & 392 & 314 \\
\hline \begin{tabular}{|l|}
12272 \\
\end{tabular} & 9854 & 435 & 349 \\
\hline 12248 & 9864 & 478 & 385 \\
\hline 12225 & 9873 & 520 & 420 \\
\hline 12200 & 9883 & 562 & 456 \\
\hline 12175 & 9893 & 604 & 491. \\
\hline 12150 & 9902 & 646 & 527 \\
\hline 12124 & 9912 & 688 & 562 \\
\hline 12098 & 9922 & 729 & 598 \\
\hline 12072 & 9932 & 777 & 634 \\
\hline
\end{tabular}


Prepared by: AJ Kostelnik Prepared by: HH Zlada

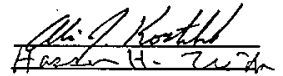

Date:

Date: $\frac{9111-48}{9-118}$

\section{Front to Rear Loading with the Front Higher than the Rear}

The graph below shows how the weight of the truck shifts to the rear jacks when the front of the truck is raised higher than the rear and shifts the center of gravity. Approximately 19518 pounds is acting on the rear jacks when the truck is level. When the front of the truck is higher than the rear, the weight on the rear reaches 19904 pounds.

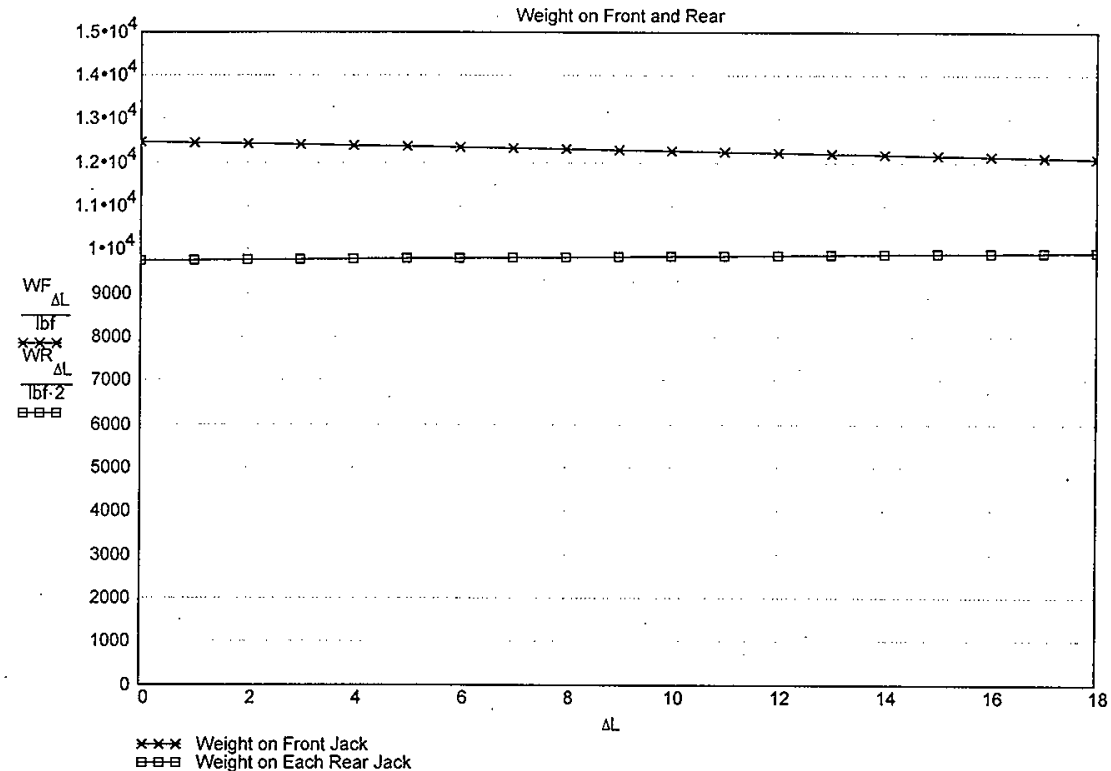

Eeight on Each Rear Jack 
Prepared by: AJ Kostelnik Prepared by:

AJ Kosteln
HH Zlada

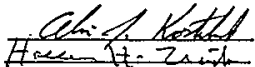

Date: $\frac{9-11-98}{9-11-90}$
Date:

\section{Front to Rear Loading with the Front Higher than the Rear. \\ Comparison with Limits from Previous Analysis.}

From the previously determined longitudinal load capability for the outriggers, determine the equivalent horizontal force capacity in the direction of front to rear at the deployment height.

Per WHC-SD-WM-ER-392, Ziada, the maximum horizontal load, front to rear, the front and rear truck jacks can withstand when extended to support the truck $18^{\prime \prime}$ from rest on level ground is 730 pounds on the Front and 500 pounds on the Rear. (On Truck \#2, the elevation creates a 42.28" moment arm on the Rear Jacks and 31.5" moment arm on the Front Jack. On Trucks $3 \& 4$, the front moment arm is 39 " and the rear moment arm is $42.28^{\prime \prime}$.)

FFlong $:=730 \cdot \mathrm{lbf}$

$H:=0 . .18 \quad$ Height of jack

Calculate the maximum moment in the bolsters to remain within limits per Truck \#2 analysis by Ziada.

$$
\begin{array}{ll}
\text { MFlong }:=\text { FFlong } \cdot 31.5 \cdot \text { in } & \text { MRlong := FRlong } 42.28 \cdot \text { in } \\
\text { MFlong }=22995 \text { elbf } \cdot \text { in } & \text { MRlong }=21140 \text { olbf } \cdot \text { in }
\end{array}
$$

Calculate the force component perpendicular to the bolster that would equal the maximum horizontal load capacity previously determined with adjustment for bolster length and truck $3 \& 4$ design. This calculation assumes the bolster sections are fully retracted and the jack feet rest on dunnage (15" under the front and $8^{* \prime}$ under the rear). (The analysis of the front jack on Truck \#2 did not drop the bolsters to the ground prior to lifting as was done for the rear jacks.)

FFmaxlong $_{H}:=\frac{\text { MFlong }}{(21+H) \cdot \text { in }} \quad$ FRmaxlong $_{H}:=\frac{\text { MRlong }}{(16.28+H) \cdot \text { in }}$

When the front of the truck is elevated the forces of concern are:

FFJH=Force on Front Jack (Horizontal component causing moment at connection)

FRJH=Force on Rear Jack (Horizontal component causing moment at connection)

FRONT

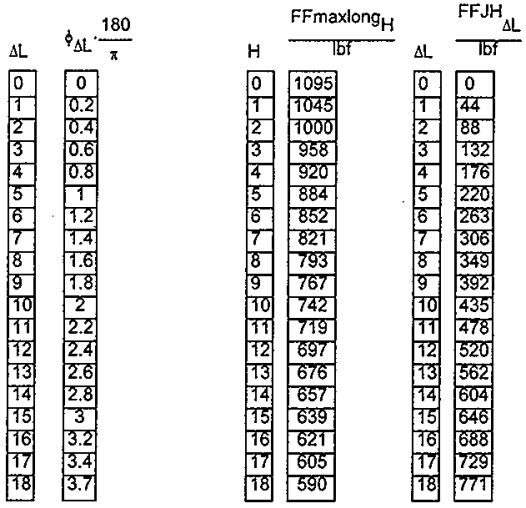

\begin{tabular}{|c|c|c|c|}
\hline \multicolumn{3}{|c|}{$\mathrm{FRmax} \operatorname{long}_{\mathrm{H}}$} & FRJH \\
\hline$H$ & $76 f$ & $\Delta L$ & $\mathrm{Tbf}$ \\
\hline 0 & 1299 & 0 & 0 \\
\hline 3 & 1223 & 7 & 35 \\
\hline 2 & 1156 & 2 & 69 \\
\hline 3 & 1096 & 3 & 104 \\
\hline 4 & 1042 & 4 & 139 \\
\hline 5 & 993 & 5 & 174 \\
\hline 6 & 949 & 6 & 200 \\
\hline 7 & \begin{tabular}{|l|}
908 \\
\end{tabular} & 7 & 244 \\
\hline 8 & \begin{tabular}{|l|}
871 \\
\end{tabular} & 8 & 279 \\
\hline 9 & \begin{tabular}{|l|}
836 \\
\end{tabular} & 9 & 314 \\
\hline 10 & \begin{tabular}{|l|l}
804 \\
\end{tabular} & 170 & 349 \\
\hline 17 & \begin{tabular}{|l|}
775 \\
\end{tabular} & मना & 385 \\
\hline 12 & 748 & 12 & 420 \\
\hline 13 & \begin{tabular}{|l|}
7222 \\
\end{tabular} & 13 & 456 \\
\hline & 698 & 14 & 491 \\
\hline 15 & 676 & 75 & 527 \\
\hline 16 & 655 & 16 & 562 \\
\hline 17 & \begin{tabular}{|l|}
635 \\
\end{tabular} & 17 & 598 \\
\hline & 617 & 18 & 634 \\
\hline
\end{tabular}

REAR 


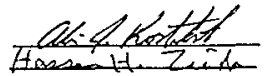

Date:

Date: $\frac{11}{0-11} 8$

Prepared by: AJ Kostelnik

Prepared by: HH Zlada

\section{Front to Rear Loading with the Front Higher than the Rear. Comparison with Limits from Previous Analysis.}

The line with $x$ 's on it below shows how the weight of the truck produces a lateral load in the front truck jack when the front is raised higher than the rear.

The line with boxes on it below shows how the weight of the truck produces a lateral load in the rear truck jacks when the front is raised higher than the rear.

The solid line shows how the longitudinal load capacity of the front jack of the truck decreases as the truck is raised.

The dotted line shows how the longitudinal load capacity of rear jacks of the truck decreases as the truck is raised.

The structural capacity of the truck is not exceeded unless the truck jacks are extended more than 15 inches. If the jacks must be extended beyond 15 inches the truck must be maintained within 3 degrees of level fromt to rear or the front jack will become overloaded.

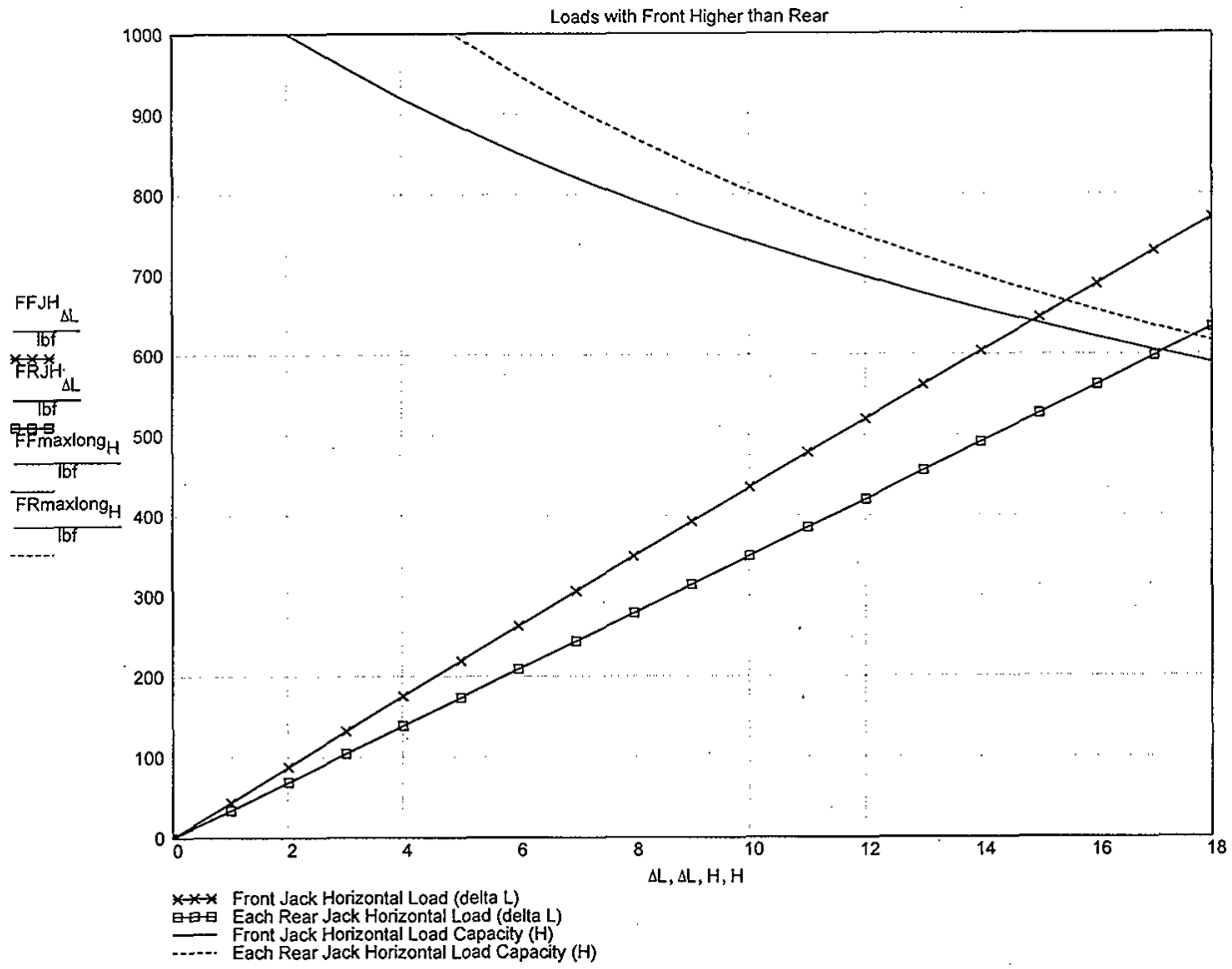


Prepared by: AJ Kostelnik Prepared by: HH Zlada

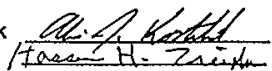

Date: $9 / 11 / 98$

Date: $\frac{9-11-48}{9-4}$

\section{Front to Rear Loading with the Rear Higher than the Front}

Calculations to show how the front jack load increases when the rear of the truck is raised higher than the front and shifts the center of gravity forward. Assume the truck weighs 32000 pounds (Trucks 3 \& 4). Reference diagram titted "REAR HIGHER THAN FRONT" (Page 14).

$\oint_{\Delta L}:=\operatorname{atan}\left(\frac{\Delta L}{282}\right)$

Angle produced by rear higher than the front. Angle from level.

Weight on both rear jacks. (Derived from moments about front jack pad.)

$$
W_{\Delta L}:=32000 \cdot 16 f \cdot \frac{172 \cdot \cos \left(\phi_{\Delta L}\right)-(46.5) \cdot \sin \left(\phi_{\Delta L}\right)}{282 \cdot \cos \left(\phi_{\Delta L}\right)+\Delta L \cdot \sin \left(\phi_{\Delta L}\right)}
$$

Weight on front jack.

$$
W F_{\Delta L}:=32000 \cdot 16 f-W R_{\Delta L}
$$

Force acting on the front and each rear jack cylinder.

$$
\mathrm{FFJ}_{\Delta \mathrm{L}}:=W F_{\Delta \mathrm{L}} \cdot \cos \left(\phi_{\Delta L}\right) \quad \text { FRJ }{ }_{\Delta L}:=\frac{W R_{\Delta L}}{2} \cdot \cos \left(\phi_{\Delta L}\right)
$$

Force component acting perpendicular to the bolsters. (The force component actually produces a bending moment in the bolster. For comparison it is projected to act at the jack pad. The "force" is produced by the weight of the truck on the leaning bolsters.)

$F F J H_{\Delta L}:=W F_{\Delta L} \cdot \sin (\phi \Delta L)$

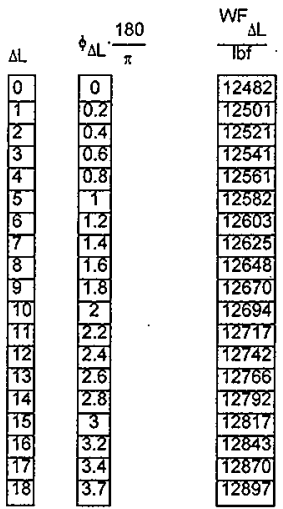

$F R J H_{\Delta L}:=\frac{W R}{2} \cdot \sin \left(\phi_{\Delta L}\right)$

$W_{\Delta L}$
Tbf
\begin{tabular}{|l|}
\hline 19518 \\
\hline 19499 \\
\hline 19479 \\
\hline 19459 \\
\hline 19439 \\
\hline 19418 \\
\hline 19397 \\
\hline 19375 \\
\hline 19352 \\
\hline 19330 \\
\hline 19306 \\
\hline 19283 \\
\hline 19258 \\
\hline 19234 \\
\hline 19208 \\
\hline 19183 \\
\hline 19157 \\
\hline 19130 \\
\hline 19103 \\
\hline
\end{tabular}

\begin{tabular}{l} 
FFJH $\Delta \mathrm{L}$ \\
\hline $16 f$ \\
\begin{tabular}{|c|}
\hline 0 \\
\hline 44 \\
\hline 89 \\
\hline 733 \\
\hline 778 \\
\hline 223 \\
\hline 268 \\
\hline 313 \\
\hline 359 \\
\hline 404 \\
\hline 450 \\
\hline 496 \\
\hline 542 \\
\hline 588 \\
\hline 634 \\
\hline 681 \\
\hline 728 \\
\hline 774 \\
\hline 822 \\
\hline
\end{tabular}
\end{tabular}

FRJH

\begin{tabular}{|c|}
\hline \multicolumn{1}{|l|}{ L } \\
\hline Tbf \\
\hline 9759 \\
\hline 9749 \\
\hline 9739 \\
\hline 9729 \\
\hline 9719 \\
\hline 9708 \\
\hline 9696 \\
\hline 9684 \\
\hline 9672 \\
\hline 9660 \\
\hline 9647 \\
\hline 9634 \\
\hline 9620 \\
\hline 9607 \\
\hline 9592 \\
\hline 9578 \\
\hline 9563 \\
\hline 9548 \\
\hline 9532 \\
\hline
\end{tabular}




\section{Prepared by: AJ Kostelnik Prepared by: HHZlada

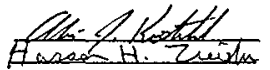 \\ Date: $9 / 1198$ \\ Date: $3 \pm 11-28$}

Front to Rear Loading with the Rear Higher than the Front

The graph below shows how the weight of the truck shifts to the front jack when the rear of the truck is raised higher than the front and shifts the center of gravity forward. Approximately +12482 pounds is acting on the front jack when the truck is level. When the rear of the truck is higher than the front, the weight on the front reaches 12871 pounds.

\section{4/K $10 / 12 / 98$}

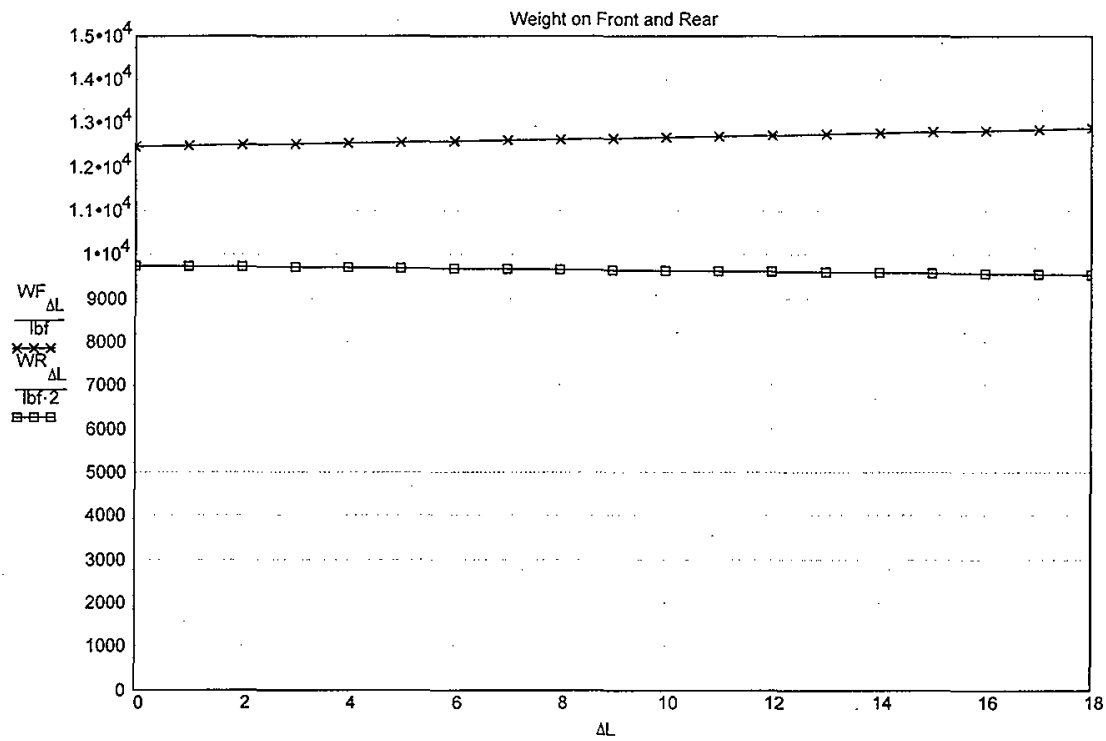

$* x-*$ Weight on Front Jack

Weight on Each Rear Jack 


\section{Prepared by: Prepared by: \\ AJ Kostelnik HH Zlada}

Date:

Date:

\section{Front to Rear Loading with the Rear Higher than the Front. Comparison with Limits from Previous Analysis.}

From the previously determined longitudinal load capability for the outriggers, determine the equivalent horizontal force capacity in the direction of front to rear at the deployment height.

Per WHC-SD-WM-ER-392, Ziada, the maximum horizontal load, front to rear, the front and rear truck jacks can withstand when extended to support the truck $18^{\prime \prime}$ from rest on level ground is 730 pounds on the Front and 500 pounds on the Rear. (On Truck \#2, the elevation creates a $42.28^{\prime \prime}$ moment arm on the Rear Jacks and 31.5" moment arm on the Front Jack. On Trucks 384 the front moment arm is $39^{\prime \prime}$ and the rear moment arm is $42.28^{n}$.)

$\mathrm{H}:=0.18 \quad$ Height of jack

Calculate the maximum moment in the bolsters to remain within limits per Truck \#2 analysis by Ziada.

$$
\begin{array}{ll}
\text { MFlong }:=\text { FFlong } \cdot 31.5 \cdot \text { in } & \text { MRlong }:=\text { FRlong } \cdot 42.28 \cdot \text { in } \\
\text { MFlong }=22995 \cdot \text { :lbf } \cdot \text { in } & \text { MRlong }=21140 \text { ॰lbf } \cdot \text { in }
\end{array}
$$

Calculate the force component perpendicular to the bolster that would equal the maximum horizontal load capacity previously determined with adjustment for bolster length and truck $3 \& 4$ design. This calculation assumes the bolster sections are fully retracted and the jack feet rest on dunnage ( $15^{\prime \prime}$ under the front and $8^{\prime \prime}$ under the rear). (The analysis of the front jack on Truck \#2 did not drop the bolsters to the ground prior to lifting as was done for the rear jacks.)
FFmaxlong $_{H}:=\frac{\text { MFlong }}{(21+H) \cdot \mathrm{in}}$
FRmaxlong ${ }_{H}:=\frac{\text { MRlong }}{(16.28+H) \cdot \text { in }}$

When the rear of the truck is elevated the forces of concem are:

FFJH=Force on Front Jack (Horizontal component causing moment at connection)

FRJH=Force on Rear Jack (Horizontal component causing moment at connection)

FRONT

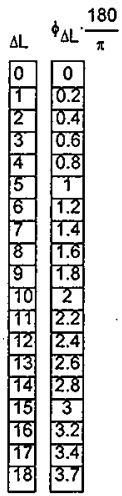

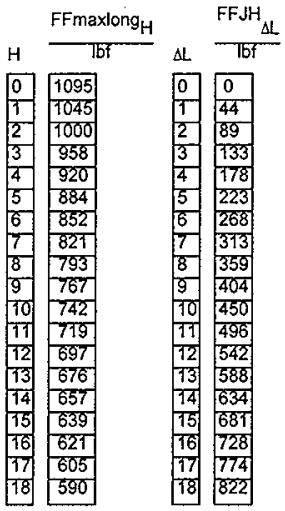

REAR

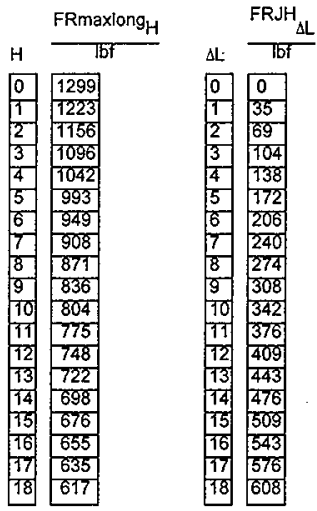


Prepared by: AJ Kostelnik

Prepared by:

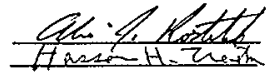

\section{Front to Rear Loading with the Rear Higher than the Front.}

Comparison with Limits from Previous Analysis.

The line with $x$ 's on it below shows how the weight of the truck produces a lateral load in the front truck jack when the rear is raised higher than the front.

The line with boxes on it below shows how the weight of the truck produces a lateral load in the rear truck jacks when the rear is raised higher than the front.

The solid line shows how the longitudinal load capacity of the front jack of the truck decreases as the truck is raised.

The dotted line shows how the longitudinal load capacity of rear jacks of the truck decreases as the iruck is raised.

The structural capacity of the truck is not exceeded unless the truck jacks are extended more than 15 inches. If the jacks must be extended beyond 15 inches the truck must be maintained within 3 degrees of level front to rear or the front jack will become overloaded.

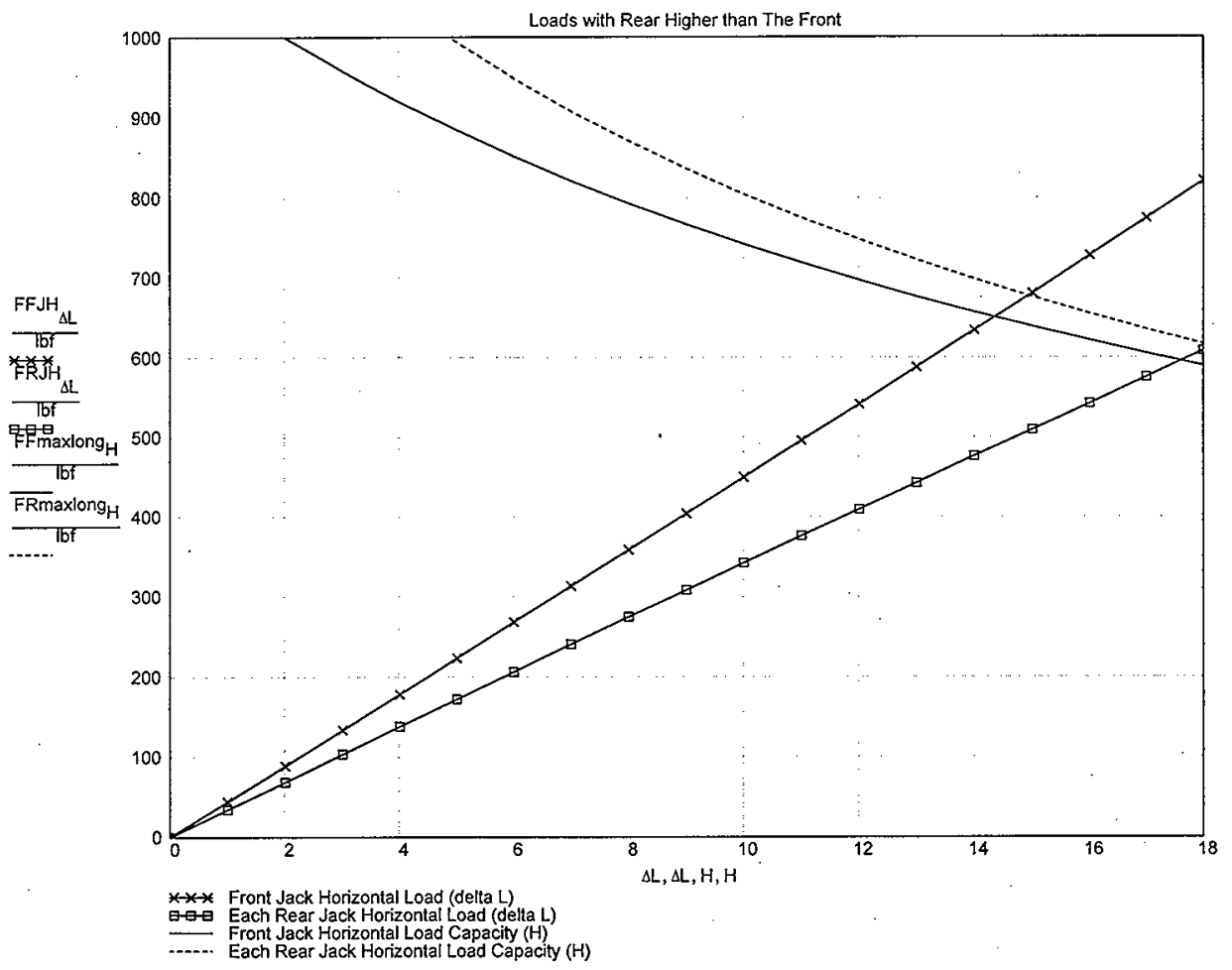


CALCULATIONS

Prepared by: AJ Kostelnik

Prepared by: HH Zlada

Free Body Diagrams for Front to Rear
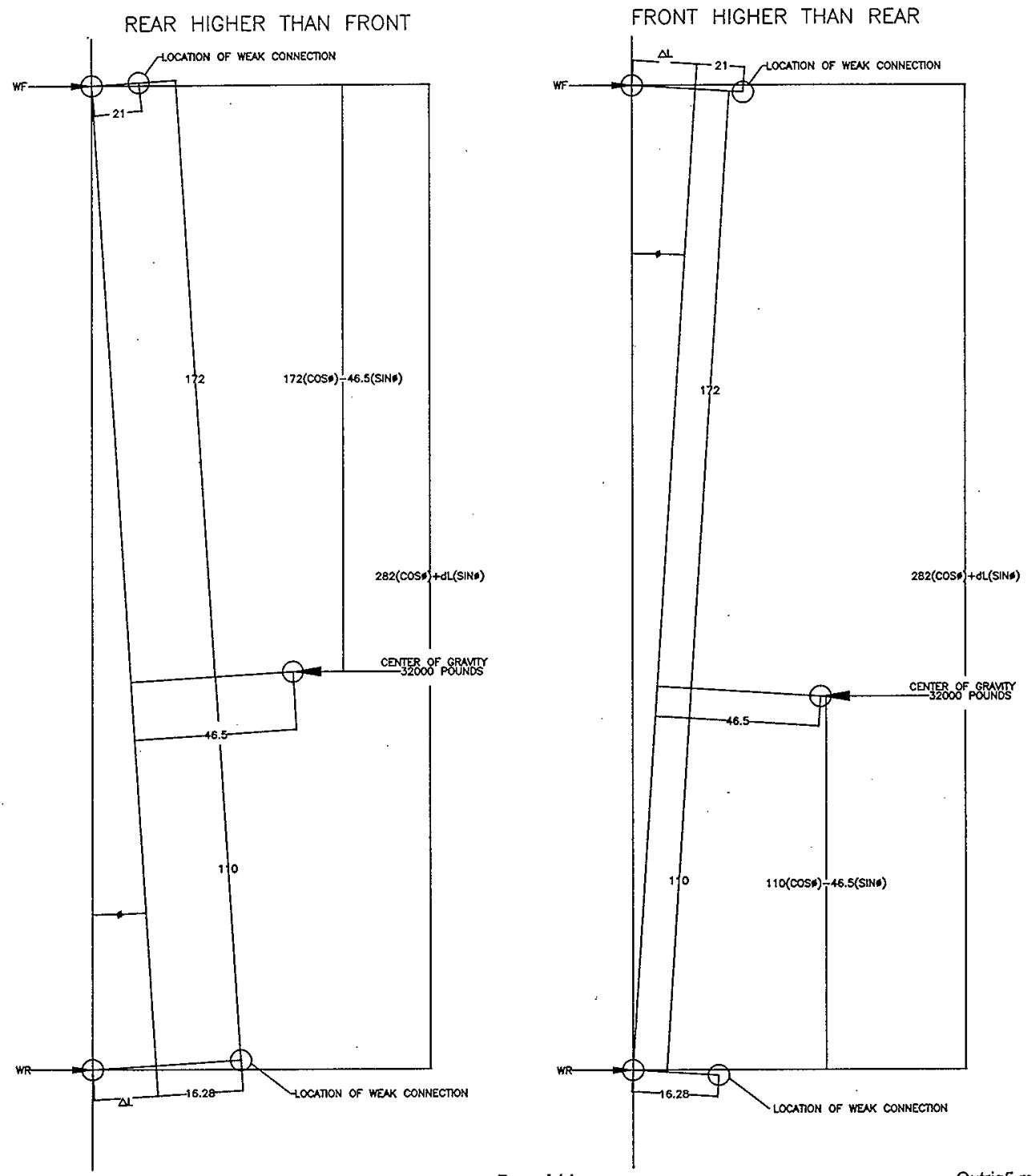

Date: 9 /11/gB

Date: $\frac{9111-98}{9-11-28}$
Date: $2=11-2 \gamma$

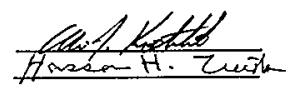


Prepared by: AJ Kostelnik Prepared by: HH Zlada
Date:

Date: $9-11-2$ o

\section{Side to Side Loading with One Side Higher than the Other}

Calculations to show how the rear jack loads change when the truck leans to the side and shifts the center of gravity. Analyzed with all jacks fully compressed with one rear jack and the front jack, both extended one inch at a time. Reference diagram titled "ONE SIDE HIGHER THAN OTHER" (Page 19.)

${ }_{\Delta \mathrm{L}}:=\operatorname{atan}\left(\frac{\Delta \mathrm{L}}{80}\right) \quad$ Angle produced with rotation around a line between a rear jack and the front jack.

WR $:=19700 \cdot 1 \mathrm{bf} \quad$ Average weight supported by the jacks on the rear of the truck from calculations on page $f$.

\section{A6}

Weight on extended (tall) rear jack.

(Derived from moments about short rear jack pad.)

Weight on front jack.

Weight on short rear jack.

WTF $_{\Delta L}:=32000 \cdot \mathrm{lbf}-\mathrm{WR}$ $W_{\Delta L}:=W R-W T R_{\Delta L}$

Force acting on jack cylinders.

FTFJ $_{\Delta L}:=W T F_{\Delta L} \cdot \cos \left(\theta_{\Delta L}\right)$

FTRJ $_{\Delta \mathrm{L}}:=\mathrm{WTR}_{\Delta \mathrm{L}} \cdot \cos \left(\theta_{\Delta \mathrm{L}}\right)$ $F_{\Delta L}:=W_{\Delta L} \cdot \cos \left(\theta_{\Delta L}\right)$

Force component acting perpendicular to the bolsters. (The force component actually produces a bending moment in the bolster. For comparison it is projected to act at the jack pad. The "force" is produced by the weight of the truck on the leaning bolsters.)

$F_{T F J H}:=W T F_{\Delta L} \cdot \sin \left(\theta_{\Delta L}\right)$

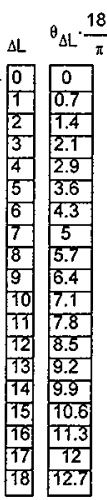

FTRJH $_{\Delta L}:=W T R_{\Delta L} \cdot \sin \left(\theta_{\Delta L}\right)$

\begin{tabular}{|c|c|c|}
\hline $\mathrm{FSRJ}_{\Delta \mathrm{L}}$ & FTRJ $_{\Delta L}$ & FTFJ $_{\Delta l}$ \\
\hline $\mathrm{Tbf}$ & Tbf & Tbf \\
\hline 9850 & 9850 & 12300 \\
\hline 9994 & 9705 & 12299 \\
\hline 10139 & 9555 & 12296 \\
\hline 10285 & 9401 & 12291 \\
\hline 10433 & 9243 & 12285 \\
\hline 10581 & 9081 & 12276 \\
\hline 10729 & 8916 & 12266 \\
\hline 10878 & 8747 & 12253 \\
\hline 11026 & 8576 & 12239 \\
\hline न1175 & 8402 & 12223 \\
\hline 11323 & 8225 & 12205 \\
\hline 11470 & 8046 & 12185 \\
\hline 11617 & 7865 & 12164 \\
\hline 11762 & 7683 & 12141 \\
\hline 11906 & 7499 & 12116 \\
\hline 12049 & 7314 & 12089 \\
\hline 12189 & 7128 & 72061 \\
\hline 12328 & 6947 & 12031 \\
\hline 12465 & 6754 & 12000 \\
\hline
\end{tabular}

$$
\text { FSRJH }_{\Delta L}:=W_{\Delta L} \cdot \sin \left(\theta_{\Delta L}\right)
$$

\begin{tabular}{|c|c|c|}
\hline FSRJH $_{\Delta \mathrm{L}}$ & FTRJH $_{\Delta L}$ & $\mathrm{FTFJH}_{\Delta}$ \\
\hline Tbf & Tbf & Tbf \\
\hline 0 . & 0 & 0 \\
\hline 125 & 727 & 154 \\
\hline 253 & 239 & 307 \\
\hline 386 & 353 & 461 \\
\hline 522 & 462 & 614 \\
\hline 661 & 568 & 767 \\
\hline 805 & 669 & 920 \\
\hline 952 & 765 & 1072 \\
\hline 1703 & 858 & 1224 \\
\hline 1257 & 945 & 1375 \\
\hline 1415 & 1028 & 1526 \\
\hline 1577 & 1106 & 1675 \\
\hline 1742 & 7180 & 1825 \\
\hline 7911 & 1248 & 1973 \\
\hline 2084 & 1312 & 2120 \\
\hline 2259 & 7371 & 2267 \\
\hline 2438 & 1426 & $24 \sqrt{2}$ \\
\hline 2620 & \begin{tabular}{|l|l|}
7475 \\
\end{tabular} & 2557 \\
\hline 2805 & 1520 & 2700 \\
\hline
\end{tabular}


Prepared by: AJ Kostelnik

Prepared by: HH Zlada

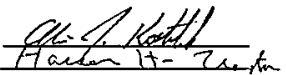

Date: $9 / 4 / 98$

Date: $\frac{919-11-48}{9}$

\section{Side to Side Loading with One Side Higher than the Other}

The graph below shows how the rear jack loads change when the truck leans to the side and shifts the center of gravity. The front jack is assumed to carry a constant 12300 pound load when the fruck leans side to side.

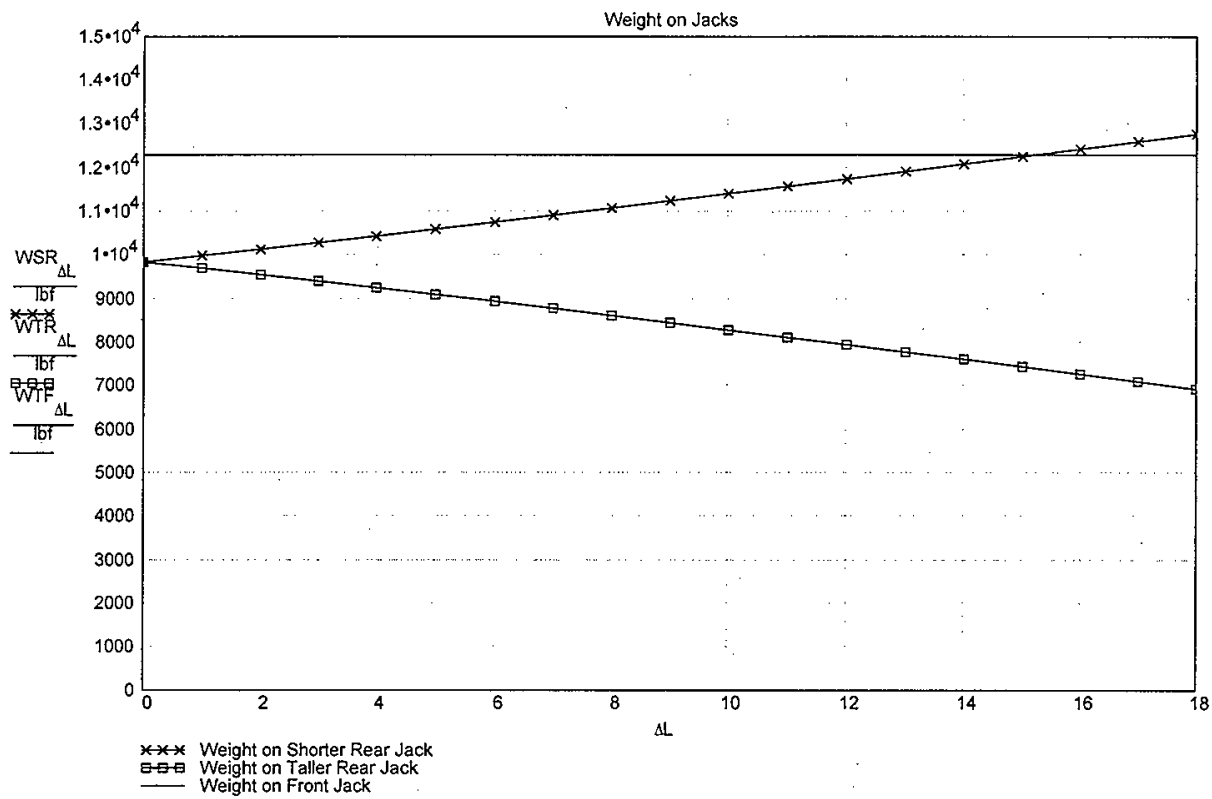




\section{Prepared by: Prepared by: \\ AJ Kostelnik
HH Zlada}

Date:

Date: $\frac{9-11-\theta}{9-1}$

\section{Side to Side Loading with One Side Higher than the Other. Comparison with Limits from Previous Analysis}

From the previously determined lateral load capability for the outriggers, determine the equivalent horizontal force capacity in the direction of side to side at the deployment height.

Per WHC-SD-WM-ER-392, Ziada, the maximum horizontal load, side to side, the front and rear truck jacks can withstand when extended to support the truck 18 " from rest on level ground is 730 pounds on the Front and 1250 pounds on the Rear. (On Truck $\# 2$, the elevation creates a $34.125^{\prime \prime}$ moment arm on the Rear Jacks and $31.5^{\prime \prime}$ moment arm on the Front Jack. On Trucks 384 the front moment arm is $39^{\prime \prime}$ and the rear moment arm is $34.125^{\prime \prime}$.)

FRlat $:=1250 \cdot 1 \mathrm{bf}$

FFlat $:=730 \cdot \mathrm{lbf}$

${ }^{\theta} \Delta L:=\operatorname{atan}\left(\frac{\Delta L}{80}\right) \quad$ Angle produced from side to side

$H:=0 . .18$ Height of jack

Calculate the maximum moment in the bolsters to remain within limits per Ziada.
MFlat := FFlat $-31.5 \cdot$ in
MRlat := FRlat $\cdot 34.125 \cdot$ in
MFlat $=22995 \cdot 10 f \cdot$ in
MRlat $=42656$ olbf $\cdot$ in

Calculate the force component perpendicular to the bolster that would equal the maximum horizontal load capacity previously determined with adjustment for bolster length and truck $3 \& 4$ design. This calculation assumes the bolster sections are fully retracted and the jack feet rest on dunnage (15" under the front and 8 " under the rear). (The analysis of the front jack on Truck \#2 did not drop the bolsters to the ground prior to
lifting as was done for the rear jacks.)

$$
\text { FFmaxiat }_{H}:=\frac{\text { MFiat }}{(21+R) \cdot \text { in }} \quad \text { FRmaxlat }_{H}:=\frac{\text { MRlat }}{(8.125+H) \cdot \text { in }}
$$

When the side of the truck is elevated the forces of concern are:

FTRJH=Force on Tall Rear Jack (Horizontal component causing moment at connection)

FSRJH=Force on Short Rear Jack (Horizontal component causing moment at connection)

FTFJH=Force on Tall Front Jack (Horizontal component causing moment at connection)
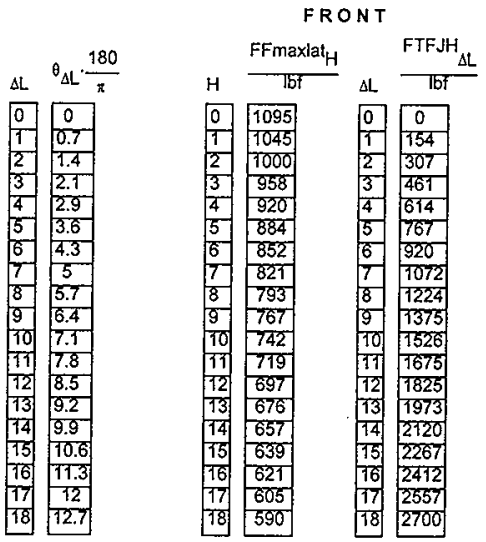

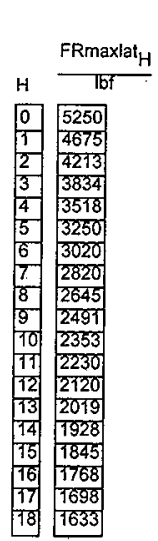

REA R

$\frac{\text { FTRJH }_{\Delta L}}{I_{\mathrm{Bf}}} \quad \frac{\text { FSRJH }_{\Delta L}}{\mathrm{BbF}}$

\begin{tabular}{|c|c|}
\hline 0 & 0 \\
\hline 121 & 125 \\
\hline 239 & 253 \\
\hline 353 & 386 \\
\hline 462 & 522 \\
\hline 568 & 661 \\
\hline 669 & 805 \\
\hline 765 & 952 \\
\hline 858 & 1703 \\
\hline 945 & 1257 \\
\hline 1028 & 1415 \\
\hline 1706 & 7577 \\
\hline 1780 & 1742 \\
\hline 1248 & 1911 \\
\hline 7372 & 2084 \\
\hline 137 & 2259 \\
\hline 1426 & 2438 \\
\hline 1475 & 2620 \\
\hline 1520 & 2805 \\
\hline
\end{tabular}


Prepared by: AJ Kostelnik Prepared by: HH Zlada

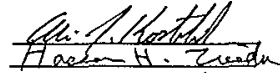

Date: $9 / 11 / 98$

Date: $\frac{9 \geq 11=9}{8}$

\section{Side to Side Loading with One Side Higher than the Other. Comparison with Limits from Previous Analysis}

The line with x's on it below shows how the weight of the truck produces a lateral load in the shorter rear truck jack when one side is raised higher than the other.

The line with boxes on it below shows how the weight of the truck produces a lateral load in the taller rear truck jack when one side is raised higher than the other.

The line with diamonds on it below shows how the weight of the truck produces a lateral load in the front truck jack when one side is raised higher than the other

The solid line shows how the lateral load capacity of the front jack of the truck decreases as the truck is raised.

The dotted line shows how the lateral load capacity of the rear jacks of the truck decreases as the truck is raised.

The structural capacity of the truck is not exceeded unless the truck jacks are extended more than 5 inches. If the jacks must be extended beyond 5 inches the truck must be maintained within 3 degrees of level from side to side or the front jack will become overfoaded.

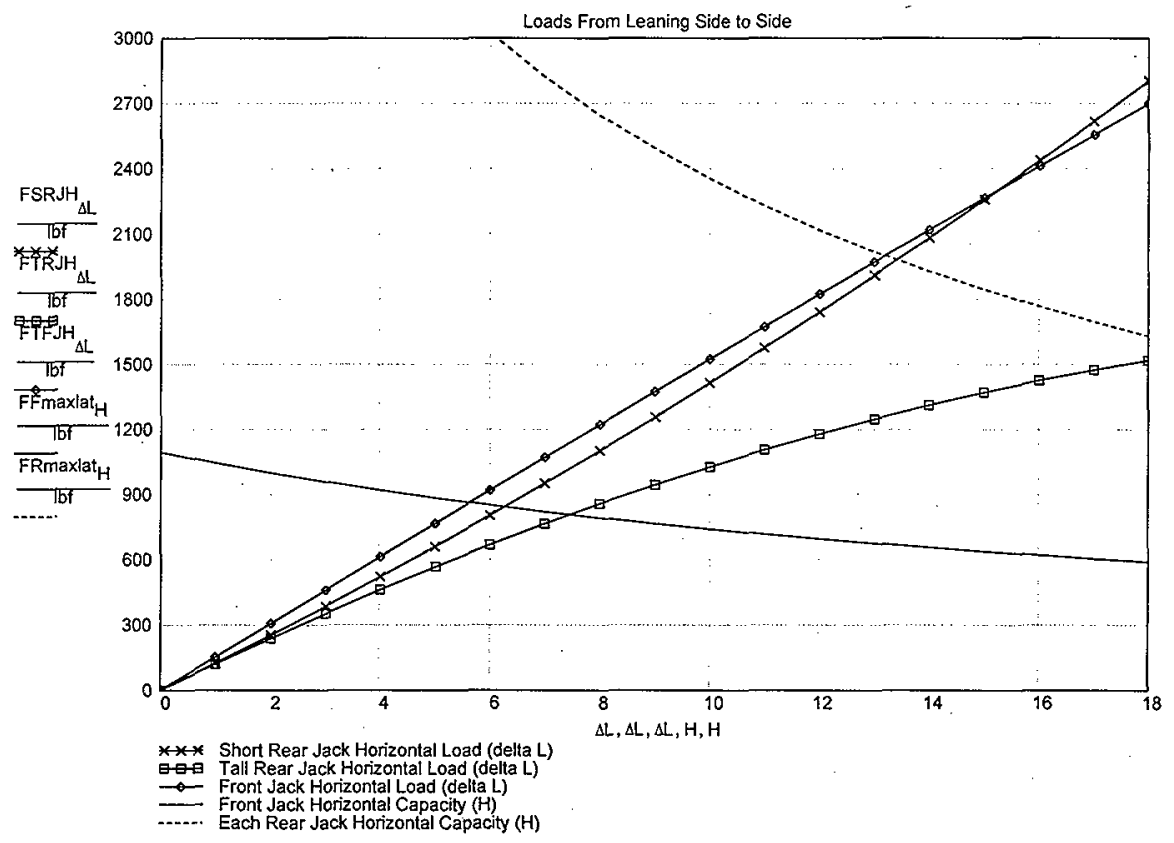


CALCULATIONS

Prepared by: AJ Kostelnik

Prepared by: HH Zlada

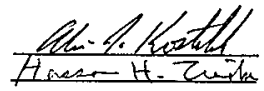

HNF-SD-WM-ETP-213

Rev.

Free Body Diagram for Side to Side

Date: $91 / 48$

Date: $\frac{9211-2}{2-11}$
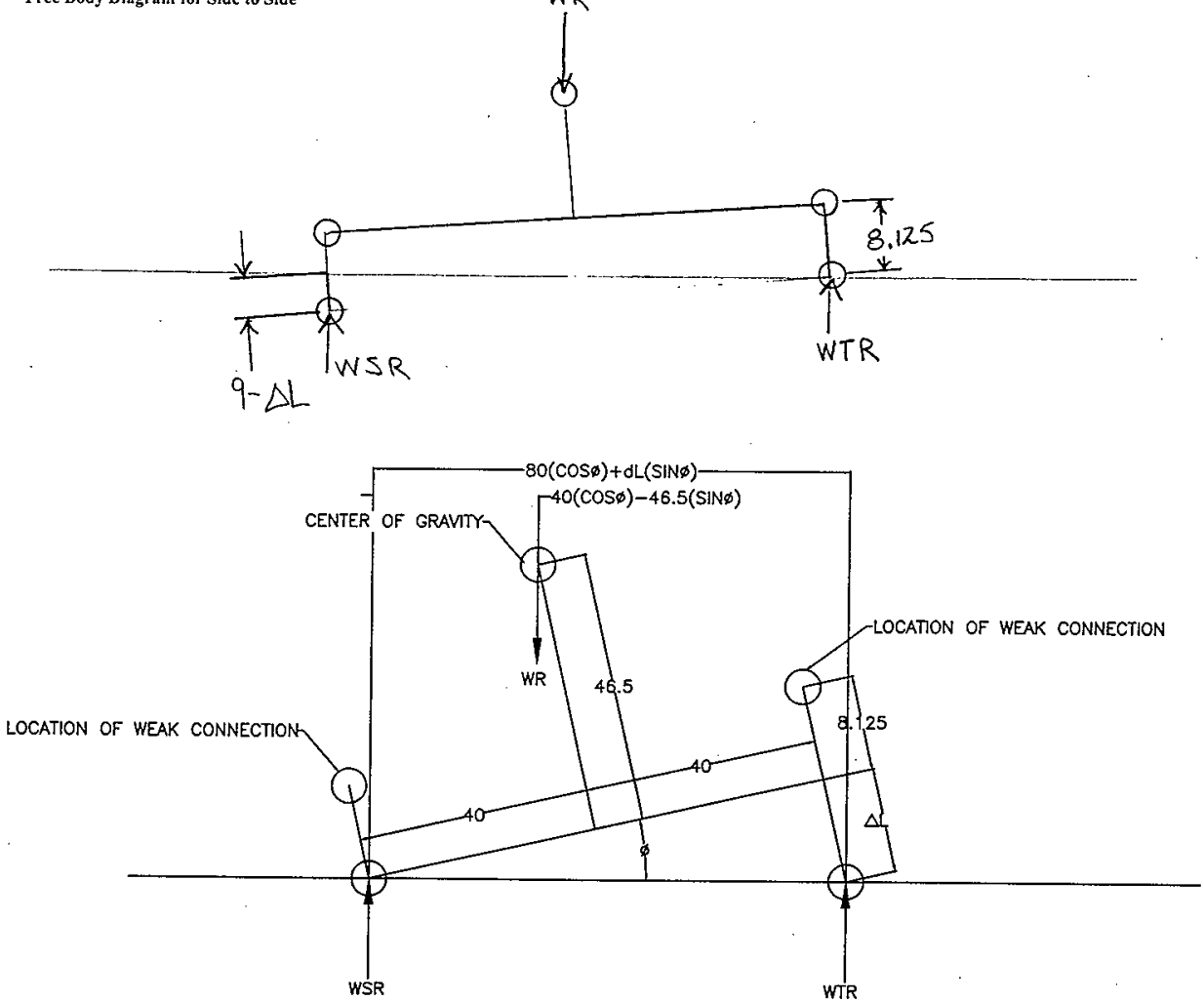

ONE SIDE HIGHER THAN THE OTHER 
Prepared by: AJ Kostelnik

Prepared by: HH Zlada

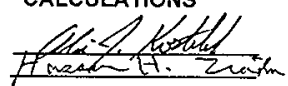

Date:

Date: $\frac{9-11-3}{y}$

\section{Check On Jack Capacity}

Calculations for the load lifting capability of the front and rear hydraulic rams for comparison to loads from leaning the truck and shifting the center of gravity. Assume the hydraulic pressure available is $1150 \mathrm{psi}$. The Outside diameter of the cylinders is $4^{\prime \prime}$ so assume the bore/piston diameter is 3.5". The front jack has 2 hydraulic cylinders.

$P:=1150 \cdot p s i$

d : $:=3.5 \cdot$ in

$A:=\pi \cdot \frac{d^{2}}{4}$

REAR := P.A

The maximum weight that each rear jack can lift is 11000 pounds. The lifting capacity is exceeded when the truck

$\mathrm{REAR}=11064 \mathrm{obf}$

8 " between the two rear rams.

FRONT : $=2 \cdot \mathrm{P} \cdot \mathrm{A}$.

FRONT $=22129 \cdot \mathrm{lbf}$

The front jacks should never become overloaded. 


\section{STARTING TO LIFT WHILE OUT OF LEVEL SIDE TO SIDE}

Calculations to show how the jack loads change when the truck leans to the side and shifts the center of gravity. Analyzed with the truck starting from a 5.7 degree lean with all jacks fully retracted and proceeding to level with the short rear jack extended one inch at a time.

$A L:=0 . .9 \quad H:=0 . .9$

${ }_{\Delta L}:=\operatorname{atan}\left(\frac{9-\Delta L}{80}\right)$

Angle produced with rotation around a line between a rear jack and the front jack. Deployment starts with one side 9 "lower than the other. Reference diagram on page At9.

WR $:=19700 \cdot \mathrm{bf}$

Average weight supported by the jacks on the rear of the truck from calculations on page A6.

Weight on extended (tall) rear jack. (Derived from moments about short rear jack pad.)

$$
\text { WTR }_{\Delta L}:=(W R) \cdot \frac{40 \cdot \cos \left(\theta_{\Delta L}\right)-46.5 \cdot \sin \left(\theta_{\Delta L}\right)}{80 \cdot \cos \left(\theta_{\Delta L}\right)+(\Delta L) \cdot \sin \left(\theta_{\Delta L}\right)}
$$

Weight on front jack.

$W_{\Delta L}:=32000 \cdot 1 b f-W R$

Force acting on jack cylinders.

FRONTCYL $L_{\Delta L}:=$ WTF $_{\Delta L} \cdot \cos \left(\theta_{\Delta L}\right)$
Weight on short rear jack.

$$
W_{S R}:=W R-W T R_{\Delta L}
$$


Date: 91198

Date: $\frac{7-11-2,5}{2-1}$

\section{STARTING TO LIFT WHILE OUT OF LEVEL SIDE TO SIDE}

The graph below shows how the rear jack loads change when the truck leans to the side and shifts the center of gravity. The front jack is assumed to carry a constant 12300 pound load when the truck leans side to side.

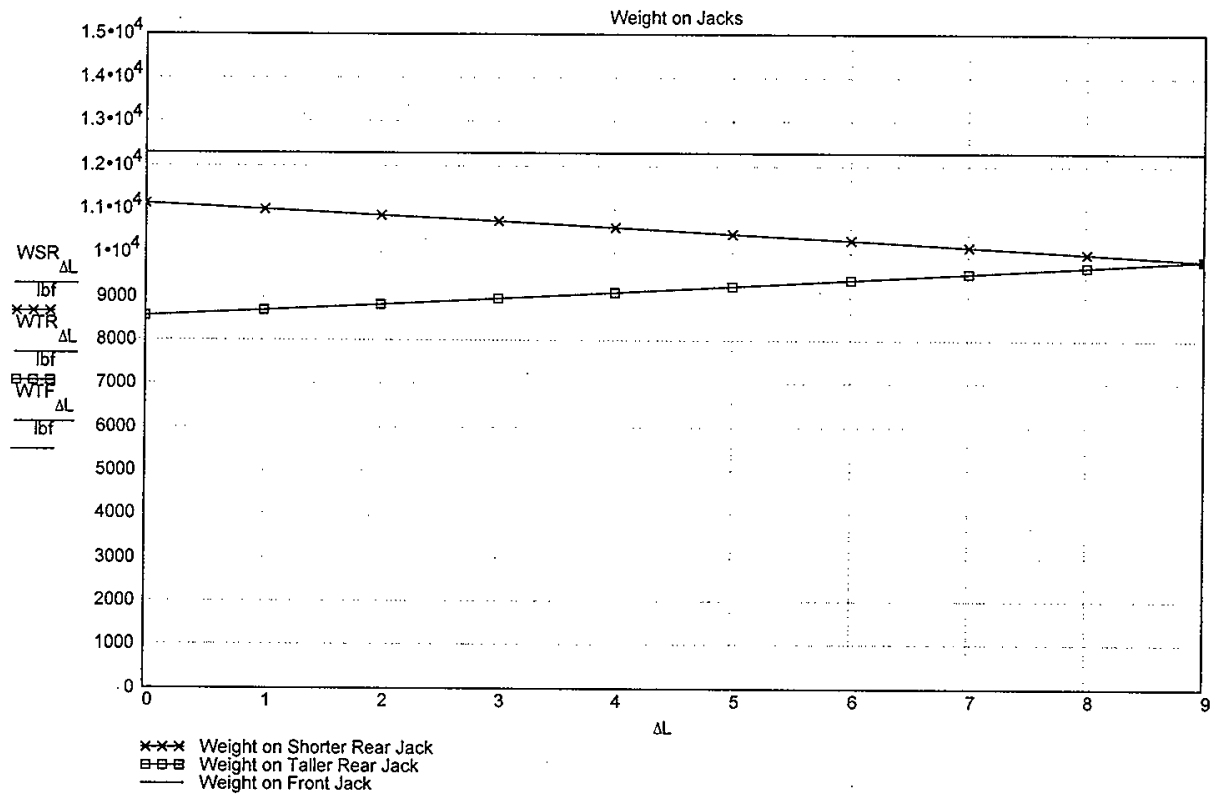




\section{CALCULATIONS}

Prepared by: AJ Kostelnik
Prepared by: HH Zlada

Date: $2 / 1188$

\section{STARTING TO LIFT WHILE OUT OF LEVEL SIDE TO SIDE Comparison with Limits from Previous Analysis}

From the previously determined lateral load capability for the outriggers, determine the equivalent horizontal force capacity in the direction of side to side at the deployment height.

Per WHC-SD-WM-ER-392, Ziada, the maximum horizontal load, side to side, the front and rear truck jacks can withstand when extended to support the truck $18^{\prime \prime}$ from rest on Jevel ground is 730 pounds on the Front and 1250 pounds on the Rear. (On Truck \#2, the elevation creates a $34.125^{\prime \prime}$ moment arm on the Rear Jacks and $31.5^{\prime \prime}$ moment arm on the Front Jack. On Trucks $3 \& 4$, the front moment arm is $39^{\prime \prime}$ and the rear moment arm is $34.125^{\prime \prime}$.)

FRlat $:=1250 \cdot \mathrm{bf}$

FFlat $:=730 \cdot 1 b f$

$\theta_{\Delta L}:=\operatorname{atan}\left(\frac{\theta-\Delta L}{80}\right)$

Angle produced from side to side

Calculate the maximum moment in the bolsters to remain within limits per Ziada.

$$
\begin{array}{ll}
\text { MFlat }:=\text { FFlat } \cdot 31.5 \cdot \text { in } & \text { MRlat }:=\text { FRlat } \cdot 34.125 \cdot \text { in } \\
\text { MFlat }=22995 \text { olbt } \cdot \text { in } & \text { MRlat }=42656 \text { olbf } \cdot \text { in }
\end{array}
$$

Calculate the force component perpendicular to the bolster that would equal the maximum horizontal load capacity previously determined with adjustment for bolster length and truck $3 \& 4$ design. This calculation assumes the bolster sections are fully retracted and the jack feet rest on dunnage ( $15^{\prime \prime}$ under the front and $8^{\prime \prime}$ under the rear). (The analysis of the front jack on Truck $\# 2$ did not drop the bolsters to the ground prior to lifting as was done for the rear jacks.)

FFmaxlat $t_{H}:=\frac{\text { MFlat }}{(21+H) \cdot \text { in }} \quad$ FRmaxlat $_{H}:=\frac{\text { MRlat }}{(8.125+H) \cdot \text { in }}$

When the truck is not level at the start the forces of concem are:

TREARHOR=Horizontal force projected to act at the foot of the higher rear jack

SREARHOR=Horizontal force projected to act at the foot of the lower rear jack

FRONTHOR=Horizontal force projected to act at the foot of the front jack

FRONT

$\theta_{\Delta L} \cdot \frac{180}{\pi}$
\begin{tabular}{|c|}
\hline 6.4 \\
\hline 5.7 \\
\hline 5 \\
\hline 4.3 \\
\hline 3.6 \\
\hline 2.9 \\
\hline 2.1 \\
\hline 1.4 \\
\hline 0.7 \\
\hline 0 \\
\hline
\end{tabular}

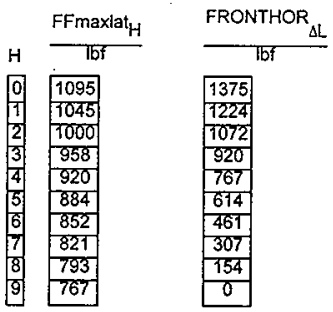

\section{RE A R}

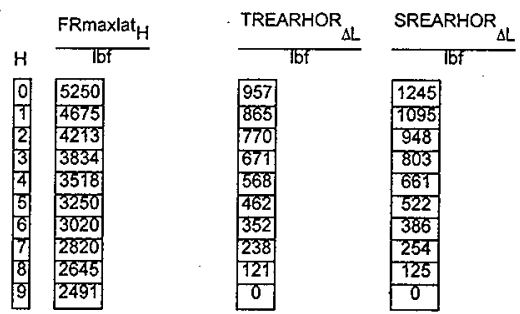




\section{CALCULATIONS \\ CALCULATIONS}

Prepared by: AJ Kostelnik
Prepared by: HH Zlada

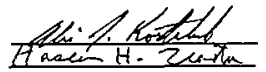

Date: $Q 14 / 96$

Date: $-9-11-98$

\section{STARTING TO LIFT WHILE OUT OF LEVEL SIDE TO SIDE Comparison with Limits from Previous Analysis}

The structural capacity of the truck is not exceeded when it feans approximately 6 degrees side to side unless the front jack is extended 3 inches or more. If the front jack must be extended beyond 3 inches before contacting the dunnage to level the truck, the truck must be within 5 degrees of level from side to side or the front jack will become overloaded. The rear jacks can withstand more lean than the front jack so 5 degrees should be the limit for initial deployment of the jacks to bring the truck to level prior to lifting.

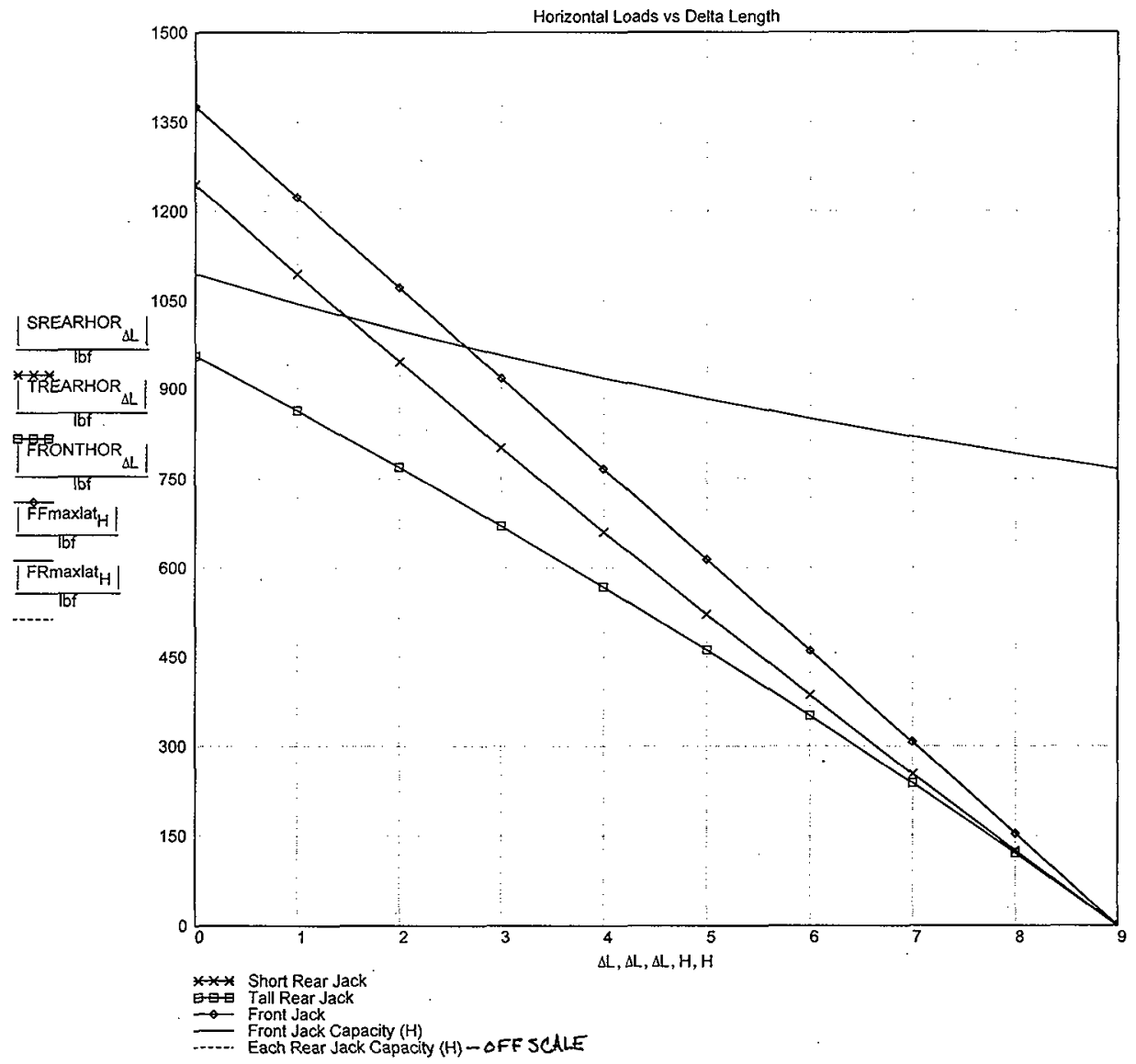




\section{Prepared by: AJ Kostelnik \\ Prepared by: $\mathrm{HH}$ Zlada}

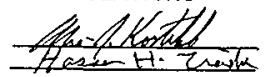

Rev.1

\section{Deployment with the Rear Higher than the Front}

Calculations to show how the front jack load increases when the rear of the truck is $24^{*}$ higher than the front and shifts the center of gravity forward. Assume the truck weighs 32000 pounds (Trucks 3 \& 4). Reference diagram titled "REAR HIGHER THAN FRONT" (Page 14).

$\Delta L:=0.18 \quad H:=0.18$

$\phi_{\Delta L}:=\operatorname{atan}\left(\frac{24-\Delta L}{282}\right) \quad \begin{aligned} & \text { Angle from level produced by the rear higher than the front. Deployment starts with the rear } 24 " \text { higher } \\ & \text { than the front. Reference diagram on page A14. }\end{aligned}$

Weight on both rear jacks. (Derived from moments about front jack pad.)

$$
W_{\Delta L}:=32000 \cdot 1 b f \cdot \frac{172 \cdot \cos \left(\phi_{\Delta L}\right)-(46.5) \cdot \sin \left(\phi_{\Delta L}\right)}{282 \cdot \cos \left(\phi_{\Delta L}\right)+\Delta L \cdot \sin \left(\phi_{\Delta L}\right)}
$$

Weight on front jack.

$$
W F_{\Delta L}:=32000 \cdot 1 b f-W R A L
$$

Force acting on the front and each rear jack cylinder.

$$
\mathrm{FFJ}_{\Delta \mathrm{L}}:=W_{\Delta \mathrm{L}} \cdot \cos \left(\phi_{\Delta L}\right) \quad F R \mathrm{FL}_{\Delta \mathrm{L}}:=\frac{W R_{\Delta L}}{2} \cdot \cos \left(\phi_{\Delta L}\right)
$$

Force component acting perpendicular to the bolsters. (The force component actually produces a bending moment in the bolster. For comparison it is projected to act at the jack pad. The "force" is produced by the weight of the truck on the leaning bolsters.)

$F_{\Delta J}:=W F_{\Delta L} \cdot \sin \left(\phi_{\Delta L}\right)$

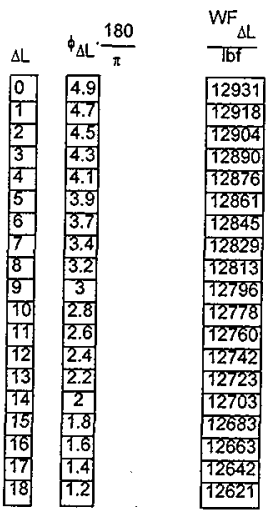

$\mathrm{FRJH}_{\Delta L}:=\frac{W R}{2} \cdot \sin \left(\phi_{\Delta L}\right)$

$W_{\Delta L}$
$\frac{W}{16 f}$
\begin{tabular}{|l|}
\hline 19069 \\
\hline 19082 \\
\hline 79096 \\
\hline 19110 \\
\hline 19124 \\
\hline 19139 \\
\hline 19155 \\
\hline 19177 \\
\hline 19187 \\
\hline 19204 \\
\hline 19222 \\
\hline 19240 \\
\hline 19258 \\
\hline 19277 \\
\hline 19297 \\
\hline 19317 \\
\hline 19337 \\
\hline 19358 \\
\hline 19379 \\
\hline
\end{tabular}

$\mathrm{FRJ}_{\Delta \mathrm{L}}$

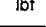

9500

9509

9519

9528

9538

9548

9558

9568

9578

9580

9599

9610

9620

9631

9642

9653

9665

9676

9687
Date:

Date:

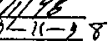


Prepared by: AJ Kostelnik Prepared by: HHZlada
Date:

Date: $\frac{2211-2}{32}$

\section{Deployment with the Rear Higher than the Front.}

The graph below shows how the weight of the truck shifts to the front jack when the rear of the truck is raised higher than the front and shifts the center of gravity forward. Approximately 12482 pounds is acting on the front jack when the truck is level. When the rear of the truck is higher than the front, the weight on the front reaches 12931 pounds.

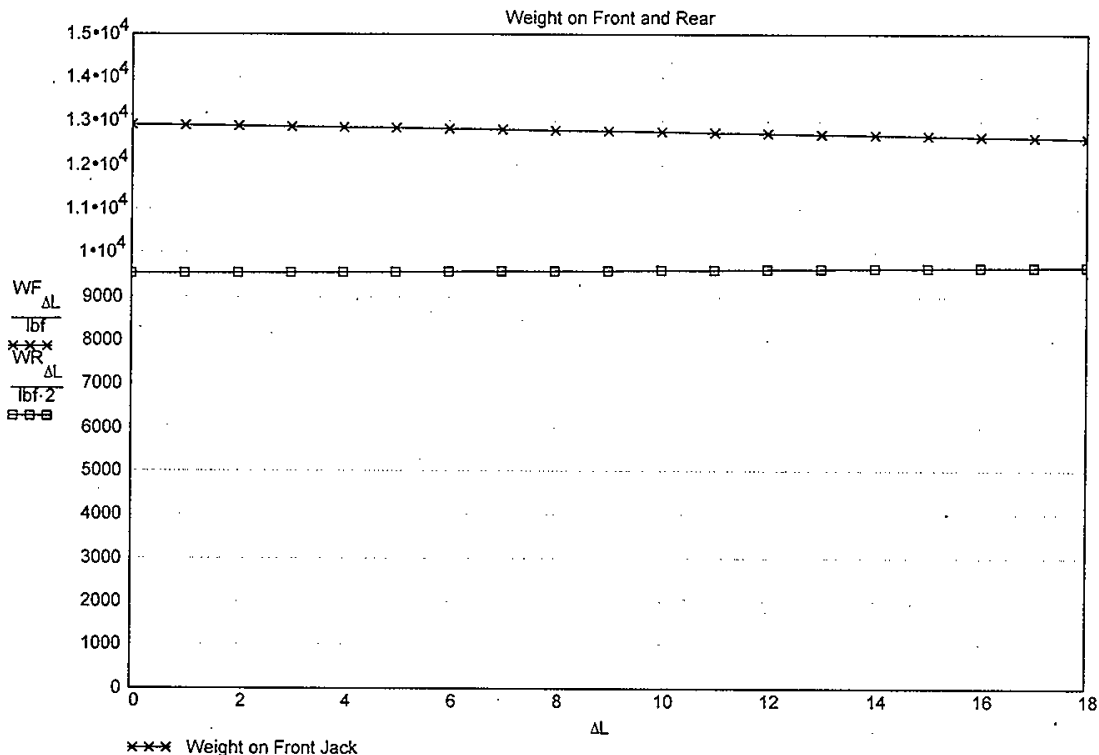

घ曰 Weight on Each Rear Jack 


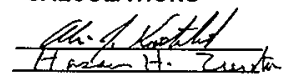

Date:

Date: $\frac{7-11-9}{9-1}$ Prepared by: AJ Kostelnik
Prepared by:

\section{Deployment with the Rear Higher than the Front.}

\section{Comparison with Limits from Previous Analysis}

From the previously determined longitudinal load capability for the outriggers, determine the equivalent horizontal force capacity in the direction of front to rear at the deployment height.

Per WHC-SD-WM-ER-392, Ziada, the maximum horizontal load, front to rear, the front and rear truck jacks can withstand when extended to support the truck 18 " from rest on level ground is 730 pounds on the Front and 500 pounds on the Rear. (On Truck $\# 2$, the elevation creates a 42,28 " moment arm on the Rear Jacks and 31.5" moment arm on the Front Jack. On Trucks 3\&4, the front moment arm is $39^{\prime \prime}$ and the rear moment arm is $42.28^{\prime \prime}$.)

FFlong : $=730 \cdot 1 \mathrm{bf}$

FRlong $:=500 \cdot \mathrm{lbf}$

$H:=0.18 \quad$ Height of jack

Calculate the maximum moment in the bolsters to remain within limits per Truck \#2 analysis by Ziada.

$\begin{array}{ll}\text { MFlong }:=\text { FFlong } \cdot 31.5 \cdot \text { in } & \text { MRlong }:=\text { FRlong } \cdot 42.28 \cdot \text { in } \\ \text { MFlong }=22995 \cdot \mathrm{lb} f \cdot \text { in } & \text { MRlong }=21140 \text { lㅣ } \cdot \text { in }\end{array}$

Calculate the force component perpendicular to the bolster that would equal the maximum horizontal load capacity previously determined with adjustment for bolster length and truck $3 \& 4$ design. This calculation assumes the bolster sections are fully retracted and the jack feet rest on dunnage ( $15^{\prime \prime}$ under the front and $8^{\prime \prime}$ under the rear). (The analysis of the front jack on Truck \#2 did not drop the bolsters to the ground prior to lifting as was done for the rear jacks.)
FFmaxlong $:=\frac{\text { MFlong }}{(21+H) \cdot i n}$
FRmaxlong $_{H}:=\frac{\text { MRlong }}{(16.28+H)-\text { in }}$

When the rear of the truck is elevated the forces of concern are:

FFJH=Force on Front Jack (Horizontal component causing moment at connection)

FRJH=Force on Rear Jack (Horizontal component causing moment at connection)

\section{FRONT}

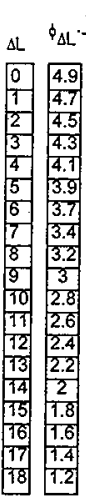

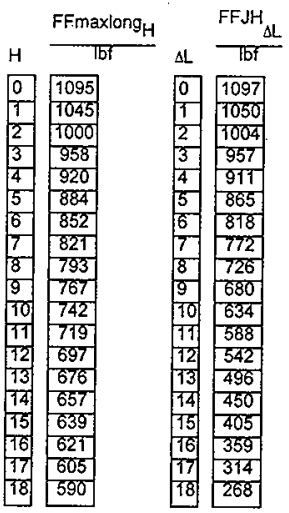

\section{REAR}

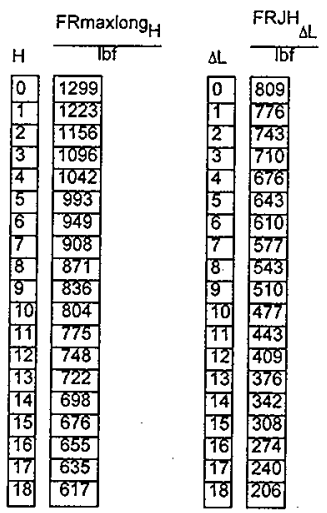

Disregard rear jack forces. The rear jacks would not be extended yet because the truck is not level. 


\section{CALCULATIONS}

Prepared by: AJ Kostelnik Prepared by: HHZlada

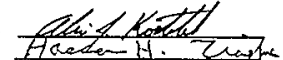

Date: $9 / 4198$

Date: $\frac{911-118}{y-118}$

\section{Deployment with the Rear Higher than the Front.}

Comparison with Limits from Previous Analysis.

The structural capacity of the truck is not exceeded unless the truck jacks are deployed with the truck at an angle of more than 5 degrees.

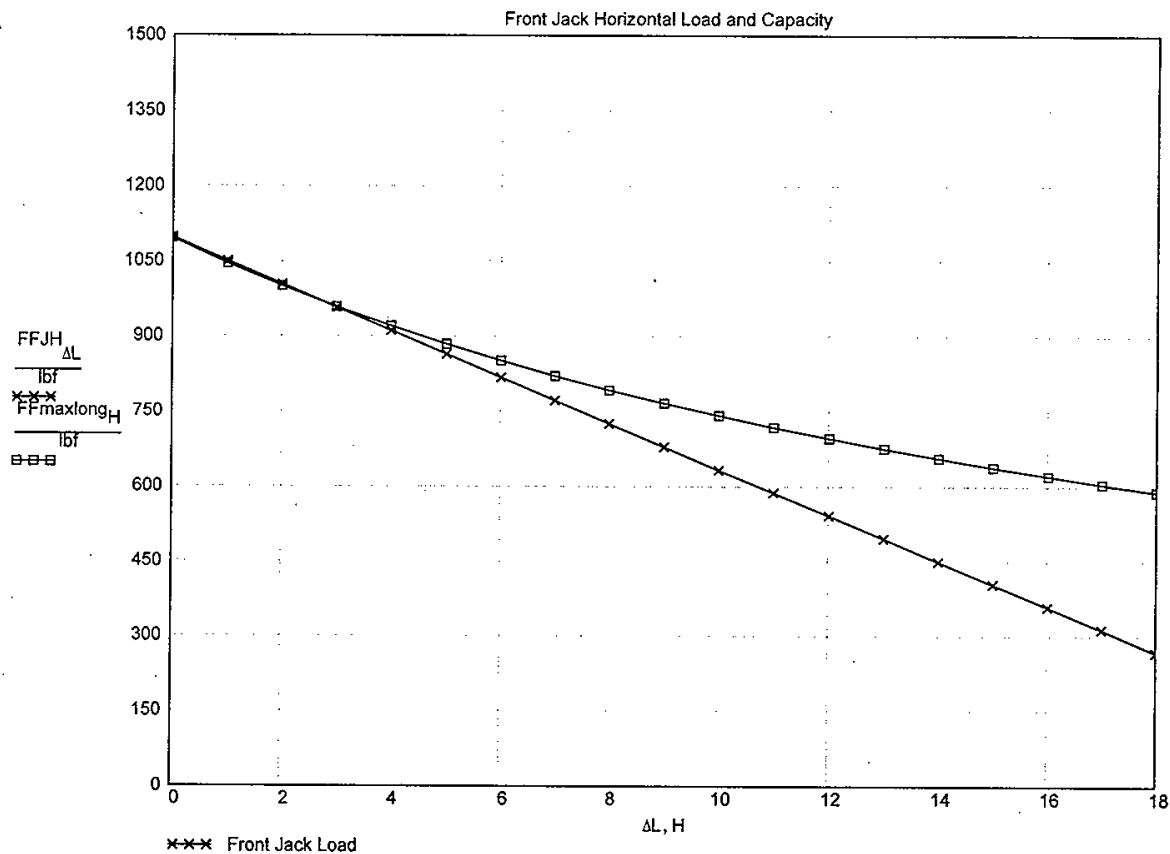

$x \rightarrow$ Front Jack Load

GQ⿱一𫝀口 Front Jack Capacity 


\section{Deployment with the Front Higher than the Rear.}

Calculations to show how the rear jack loads increase when the front of the truck is raised higher than the rear and shifts the center of gravity backwards. Assume Trucks 3 \& 4 weigh 32000 pounds. Reference diagram titled "FRONT HIGHER THAN REAR" (Page 14).

Date:

$\Delta L:=0.18 \quad$ Difference in jack length.

$\phi_{\Delta L}:=\operatorname{atan}\left(\frac{30-\Delta L}{282}\right)$

Angle from level produced by the front higher than the rear. Deployment starts with the front $30^{\prime \prime}$ higher than the rear. Reference diagram on page Ait.

Weight on front jack (Derived from moments about rear jack pad)

$$
W_{\Delta L}:=32000 \cdot 1 \mathrm{bF} \cdot \frac{110 \cdot \cos \left(\phi_{\Delta L}\right)-(46.5) \cdot \sin \left(\phi_{\Delta L}\right)}{282 \cdot \cos \left(\phi_{\Delta L}\right)+\Delta L \cdot \sin \left(\phi_{\Delta L}\right)}
$$

Weight on rear jacks.

$$
W R_{\Delta L}:=32000 \cdot 1 b f-W F_{\Delta L}
$$

$F F J_{\Delta L}:=W F_{\Delta L} \cdot \cos \left(\phi_{\Delta L}\right) \quad \quad F R J_{\Delta L}:=\frac{W R}{2} \cdot \cos \left(\phi_{\Delta L}\right) \quad$ Axial force acting on the front and each rear jack $\underline{c y l i n d e r}$.

Force component acting perpendicular to the bolsters. (The force component actually produces a bending moment in the bolster. For

\begin{tabular}{|c|c|c|c|c|c|c|}
\hline \multicolumn{3}{|c|}{$F F J H_{\Delta L}:=W F_{\Delta L} \cdot \sin (\phi \Delta L)$} & \multicolumn{4}{|c|}{$W_{A L}$} \\
\hline$\phi_{\Delta L} \cdot \frac{180}{\pi}$ & $\frac{W_{A L}}{T b f}$ & 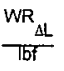 & $\frac{F F J_{\Delta L}}{16 f}$ & $\frac{\text { FRJ }_{\Delta L}}{\frac{\Delta L f}{16 f}}$ & $\frac{\mathrm{FFJH}_{\Delta \mathrm{L}}}{\mathrm{IBf}}$ & $\frac{\text { FRJH }_{\Delta L}}{16 f}$ \\
\hline 6.1 & 11921 & 20079 & 11854 & 9983 & 1261 & 1062 \\
\hline 5.9 & 77935 & 20065 & 17873 & 9980 & 1221 & \begin{tabular}{|l|}
1002 \\
1026 \\
\end{tabular} \\
\hline \begin{tabular}{|l|}
5.7 \\
5.5
\end{tabular} & 11950 & 20050 & 11891 & 9976 & 1181 & 991 \\
\hline (5.5 & 71965 & 20035 & 11910 & 9972 & 1140 & 955 \\
\hline$\frac{5.3}{5.1}$ & 17980 & 20020 & 17930 & 9968 & 1100 & 979 \\
\hline 4.9 & \begin{tabular}{|l|}
111996 \\
3201
\end{tabular} & 20004 & 11949 & 9963 & 1059 & 883 \\
\hline \begin{tabular}{|l|}
4.7 \\
\end{tabular} & 12028 & $\begin{array}{l}199891 \\
19972\end{array}$ & \begin{tabular}{|l|}
11968 \\
\end{tabular} & 9958 & 1019 & 848 \\
\hline 4.5 & 12044 & \begin{tabular}{|l|}
19956 \\
\end{tabular} & 12007 & 9953 & 978 & 812 \\
\hline 4.3 & 12061 & \begin{tabular}{|l|}
19939 \\
\end{tabular} & & 9948 & 937 & 776 \\
\hline 4.1 & 12078 & 19922 & & 9942 & 896 & 740 \\
\hline 3.9 & 12095 & 19905 & & 9936 & 854 & 705 \\
\hline 3.7 & 12173 & 79887 & & 9930 & 813 & 669 \\
\hline 3.4 & 12130 & 19870 & 12088 & 9924 & 772 & 633 \\
\hline 3.2 & 12149 & 19857 & 12708 & 9917 & 730 & 598 \\
\hline 3 & 12767 & 19833 & 12129 & 9910 & 688 & 562 \\
\hline 2.8 & 12186 & 19814 & 172150 & 9902 & 646 & 527 \\
\hline 2.6 & 12205 & 19795 & $121 / 1$ & 9895 & 604 & 491 \\
\hline 2.4 & 12225 & 19775 & 12192 & 9887 & 562 & 456 \\
\hline & & & 12213 & 9879] & 520 & 420 \\
\hline
\end{tabular}
comparison it is projected to act at the jack pad. The "force" is produced by the weight of the truck on the leaning bolsters.) 


\section{CALCULATIONS \\ Prepared by: AJ Kostelnik Prepared by: HH Zlada

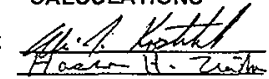 \\ Date: $9 / 1 / 88$ \\ Date: $\frac{9-11-98}{9-9}$}

\section{Deployment with the Front Higher than the Rear.}

The graph below shows how the weight of the truck shifts to the rear jacks when the front of the truck is raised higher than the rear and shifts the center of gravity. Approximately 19518 pounds is acting on the rear jacks when the truck is level. When the front of the iruck is higher than the rear, the weight on the rear reaches 20079 pounds.

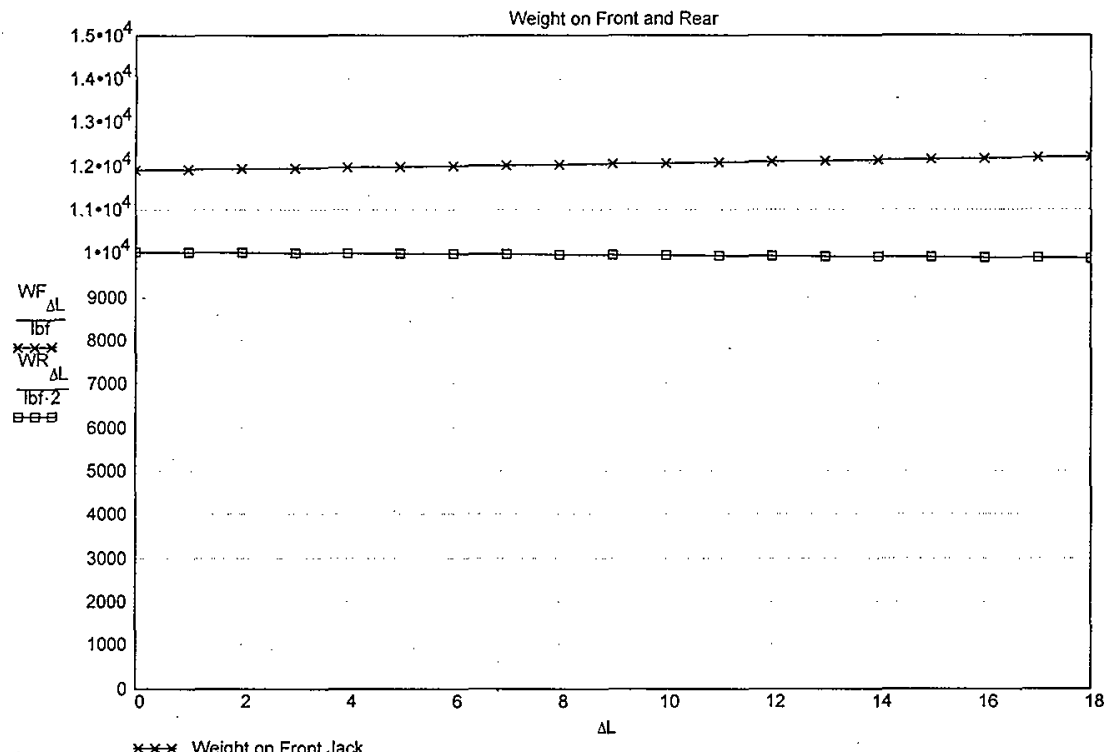

E-g日 Weight on Each Rear Jack 


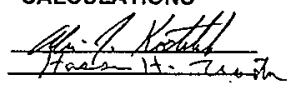

\section{Prepared by: AJ Kostelnik Prepared by: HH Zlada}

Date: $711 / 98$

Date: A.wo $9-11-9 \overline{8}$

\section{Deployment with the Front Higher than the Rear. Comparison with Limits from Previous Analysis.}

From the previously determined longitudinal load capability for the outriggers, determine the equivalent horizontal force capacity in the direction of front to rear at the deployment height.

Per WHC-SD-WM-ER-392, Ziada, the maximum horizontal load, front to rear, the front and rear truck jacks can withstand when extended to support the truck 18" from rest on level ground is 730 pounds on the Front and 500 pounds on the Rear. (On Truck \#2, the elevation creates a $42.28^{\prime \prime}$ moment arm on the Rear Jacks and $31.5^{\prime \prime}$ moment arm on the Front Jack. On Trucks $3 \& 4$, the front moment arm is $39^{\prime \prime}$ and the rear moment arm is $42.28^{\prime \prime}$.)

FFlong : $=730 \cdot 1 \mathrm{bf}$

$H:=0 . .18 \quad$ Height of jack

Calculate the maximum moment in the bolsters to remain within limits per Ziada.

Calculate the force component perpendicular to the bolster that would equal the maximum horizontal load capacity previously determined with adjustment for bolster length and truck $3 \& 4$ design. This calculation assumes the bolster sections are fully retracted and the jack feet rest on dunnage (15" under the front and 8 " under the rear). (The analysis of the front jack on Truck $\# 2$ did not drop the bolsters to the ground prior to lifting as was done for the rear jacks.)

FFmaxlong $_{H}:=\frac{\text { MFlong }}{(21+H) \cdot \text { in }} \quad$ FRmaxiong $_{H}:=\frac{\text { MRlong }}{(16.28+H) \cdot \text { in }}$

When the front of the truck is elevated the forces of concern are:

FFJH=Force on Front Jack (Horizontal component causing moment at connection)

FRJH=Force on Rear Jack (Horizontal component causing moment at connection)

FRONT

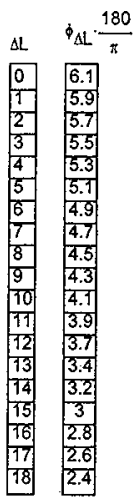

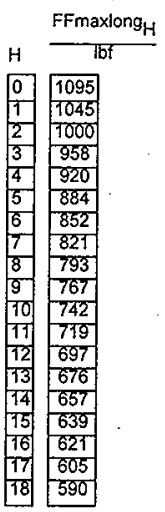

REA R

\begin{tabular}{|c|c|c|c|}
\hline \multirow[b]{2}{*}{$\mathrm{H}$} & FRmaxlong & \multirow[b]{2}{*}{$\Delta \mathrm{L}$} & $\mathrm{FRJH}_{\Delta \mathrm{L}}$ \\
\hline & Tbf & & $76 f$ \\
\hline 0 & 1299 & 0 & 1062 \\
\hline 1 & 1223 & 1 & 1026 \\
\hline 2 & 1156 & 2 & \begin{tabular}{|l|}
991 \\
\end{tabular} \\
\hline 3 & 1096 & 3 & 955 \\
\hline 4 & 1042 & 4 & 919 \\
\hline 5 & 993 & 5 & 883 \\
\hline 6 & 949 & 6 & \begin{tabular}{|l|}
848 \\
\end{tabular} \\
\hline 7 & 908 & 7 & 812 \\
\hline 8 & 871 & 8 & \begin{tabular}{|l|}
776 \\
\end{tabular} \\
\hline 9 & 836 & 9 & 740 \\
\hline 10 & 804 & 10 & \begin{tabular}{|l|}
705 \\
\end{tabular} \\
\hline 111 & 775 & री & 669 \\
\hline 12 & 748 & 12 & 633 \\
\hline 13 & 722 & 13 & 598 \\
\hline 14 & 698 & 14 & 562 \\
\hline 15 & 676 & \begin{tabular}{|l|}
15 \\
\end{tabular} & \begin{tabular}{|l|}
527 \\
\end{tabular} \\
\hline 16 & 655 & 16 & 499 \\
\hline 17 & 635 & 17 & \begin{tabular}{|l|}
456 \\
\end{tabular} \\
\hline 18 & 617 & 18 & 420 \\
\hline
\end{tabular}

Disregard front jack forces. The front jack would not be extended yet because the truck is not level. 
Prepared by: AJ Kostelnik

Prepared by: $\mathrm{HH}$ Zlada

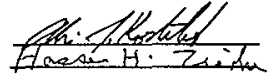

Date: $9 / 11 / 98$

Date: $-\frac{9-11-98}{9-8}$

Deployment with the Front Higher than the Rear.

Comparison with Limits from Previous Analysis.

The structural capacity of the truck is not exceeded unless the truck jacks are deployed with the rear of the truck more than 30 inches below the front Level the truck within 6 degrees of level front to rear or the rear jacks will become overloaded.

The angle of inclination is bounded by the 5 degree limit established for the condition of the rear higher than the front

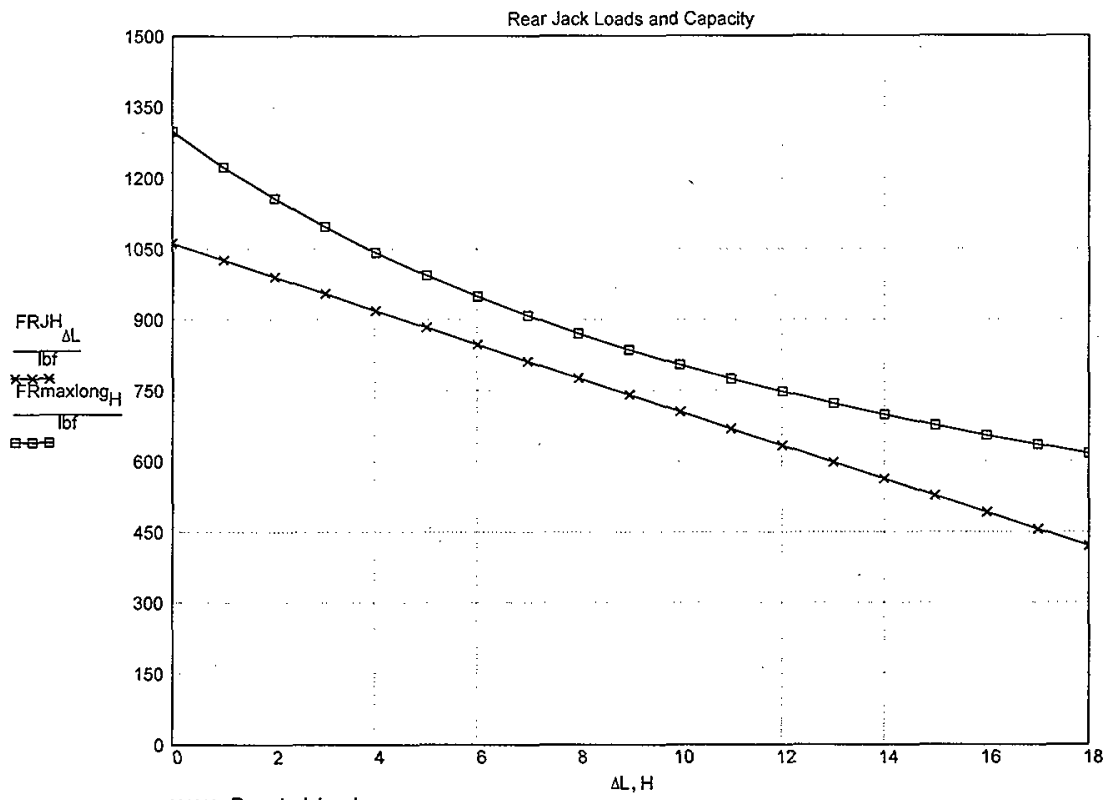

$* * *$ Rear Jack Loads

Rear Jack Capacity 